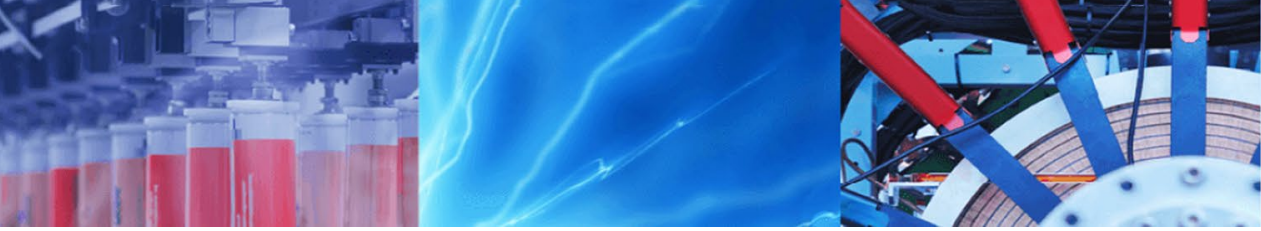

Research Article

\title{
Design of advanced artificial intelligence protection technique based on low voltage ride-through grid code for large-scale wind farm generators: a case study in Egypt
}

\author{
Omar Noureldeen $^{1}$ (D) I. Hamdan ${ }^{1}$ (D) B. Hassanin ${ }^{2}$
}

(c) Springer Nature Switzerland AG 2019

\begin{abstract}
This paper proposes an advanced artificial intelligence protection technique based on low voltage ride-through (LVRT) for a large-scale doubly fed induction generator (DFIG) wind farm. The proposed protection technique consists of two dependant approaches. The first approach is fault detector algorithm that using adaptive neuro fuzzy inference system as an artificial intelligence technique to detect the fault occurrence and its location. The second approach is implementation of Egyptian LVRT grid code to discriminate between tripping or not tripping decision for faulted wind turbine generators based on fault conditions such as its duration and voltage level. The proposed protection technique is applied on a simulation model of 200 MW Gabal El-Zayt wind farm, which located in Red Sea region and connected to Egyptian electrical grid. The studied wind farm consists of 100 DFIG wind turbines, and each generator has a capacity of 2 MW. The simulation model of studied wind farm is implemented by using MATLAB/SIMULINK toolboxes to demonstrate the performance of proposed protection technique. The impacts of fault duration, fault type, internal and external fault locations on the behaviour of studied wind farm equipped with the proposed protection technique are investigated. Also, the impacts of grid voltage sag and different ground transition resistances on the performance of proposed protection technique are investigated. The simulation results show that, the proposed protection technique can detect and isolate the faulted area according to Egyptian LVRT grid code requirements for enhancement the stability of studied wind farm.
\end{abstract}

Keywords ANFIS networks · DFIG · Egyptian LVRT grid code · Large-scale wind farm · Fault detector

\section{Introduction}

The increasing penetration level of wind farm in Egyptian electrical power grid has major impacts [1]. The strategy of new and renewable energy authority (NREA) in Egypt aims to increase the contribution of wind energy by $12 \%$ of the total electricity generation which is translating to 7200 MW by year 2020 [2]. Gabal El-Zayt region is located along the coast of Red Sea region in Egypt, where it is classified as an excellent wind speed site [3, 4]. The currently installed wind power capacity in Gabal El-Zayt exceeds $580 \mathrm{MW}$ deliverd to Egyptian electrical grid [2]. The implemented projects of Gabal El-Zayt wind farms are divided into two projects. The first project is Gabal El-Zayt 1 wind farm with a capacity of $200 \mathrm{MW}$ and it consists of 100 wind turbines, where it is extended to $240 \mathrm{MW}$. The second project is Gabal El-Zayt 2 wind farm with a capacity of $220 \mathrm{MW}$ and it consists of 110 wind turbines. Also, the third under construction project is $120 \mathrm{Gabal}$ El-Zayt 3 wind farm, which it consists of 60 wind turbines. The variable speed DFIG wind turbine technology is utilized in Gabal El-Zayt due to their high energy efficiency. On the other hand, the DFIG is very sensitive to grid faults because of the stator windings are connected directly to the grid. The sudden change of stator windings voltage during faults may cause over current and over voltage in rotor windings due to

$\triangle$ Omar Noureldeen, omar_noureldeen@svu.edu.eg | ${ }^{1}$ Department of Electrical Engineering, Faculty of Engineering, South Valley University, Qena 83523, Egypt. ${ }^{2}$ Electrical Engineering Department, Faculty of Engineering, Al-Azhar University, Qena, Egypt.

SN Applied Sciences (2019) 1:515 | https://doi.org/10.1007/s42452-019-0538-9 
magnetic coupling [5]. To avoid the damage of DFIG power electronic components, extra protection techniques must be established [6-10]. Currently, the grid code requires that the wind farm must remain connected to electrical grid for a specified duration time during faults, which is so-called LVRT grid code curve of wind turbines [11]. The electrical grid voltage will drop further if the wind turbines are tripped off immediately after fault occurrence. Therefore, the power plant system may be failed due to cascaded tripping of wind turbine generators. To prevent power system failure, the wind turbine generators must be driven by the LVRT requirements [12]. Moreover, the wind turbine generators require a protection technique that usually adopted in order to improve and achieve LVRT requirements. As mentioned earlier that, the different protection techniques for DFIG based wind turbine in case of short circuit faults are introduced in [13-20]. The justified fault ride through requirements for wind turbines in power systems are introduced in [21]. The technologies of fault ride through capability to protect the DFIG wind turbines components are mentioned in [22]. The implementation of the LVRT curve for protection system of wind turbine is presented in [23]. Many researchers have focused their attentions on the LVRT capabilities enhancement for DFIG wind turbines [24-28]. The improvement of fault ride through capability for wind turbine driven by DFIG is introduced in [29-34]. The design of DFIG active and reactive power control using energy storage system and static synchronous compensator is introduced [35]. Also, other approaches based on current control besides for design of electro-motor-force, flux control, and demagnetization control with DFIG based wind turbines are introduced in [36-44]. The ANFIS algorithm is utilized as a protection and control system for wind turbine generators as described in $[5,7,14,45-47]$. As the wind farms increase in capacity, they are essentially to stay connected to the grid. The contribution of this paper concentrates on preventing the wind turbine generators disconnection during faults based on LVRT requirements to enhance the stability of wind farm power system. This paper proposes a design of protection technique for $200 \mathrm{MW}$ Gabal El-Zayt wind farm based on ANFIS fault detector and implementation of Egyptian LVRT grid code. Also, the proposed protection technique is designed to discriminate between fault occurrence and voltage sag during voltage dip conditions. The simulation study is carried out at various fault conditions to validate the robustness of proposed protection technique. The impacts of various fault conditions such as fault duration for different fault types, internal and external fault locations, grid voltage sag, and different ground transition resistances on the performance of proposed protection technique are investigated. This paper is prepared as follows: Sect. 2 explains the model and control strategy of
DFIG system. Section 3 describes the Egyptian LVRT grid code for wind turbines. Section 4 describes the proposed protection technique based on ANFIS fault detector and Egyptian LVRT grid code. Section 5 presents the simulation of studied 200 MW Gabal El-Zayt wind farm. Section 6 illustrates the results and analysis. Section 7 illustrates the discussion of the proposed protection technique. Section 8 contains the conclusion.

\section{DFIG model and control strategy}

The DFIG wind turbine system consists of wind turbine, gearbox, power electronic converters such as rotor-side converter (RSC) and grid-side converter (GSC), DC-link capacitor (DCLC), grid filter, and coupling transformers to electrical grid. As shown in Fig. 1, the stator windings are connected directly to the grid, while the rotor windings are fed through bidirectional converters and connected to the grid through a filter to reduce the distortions caused by converters.

The DFIG can be represented by the equivalent circuits in popular direct-quadrature $(\mathrm{d}-\mathrm{q})$ reference frame as shown in Fig. 2. Also, the dynamic model of DFIG can be analyzed by the appropriate $d$-q reference frame $[14,15]$. The stator voltage in the $d$-q reference frame is given as follows:

$V_{d s}=R_{s} I_{d s}-\omega_{e} \lambda_{q s}+d \lambda_{d s} / d t$

$V_{q s}=R_{s} l_{q s}+\omega_{e} \lambda_{d s}+d \lambda_{q s} / d t$

Similarly, the rotor voltage in the $\mathrm{d}$-q reference frame is given as follows:

$V_{d r}=R_{r} I_{d r}-\left(\omega_{e}-\omega_{r}\right) \lambda_{q r}+d \lambda_{d r} / d t$

$V_{q r}=R_{r} I_{q r}+\left(\omega_{e}-\omega_{r}\right) \lambda_{d r}+d \lambda_{q r} / d t$

The stator flux linkage in the $d$-q reference frame is given as follows:

$\lambda_{d s}=L_{s} I_{d s}+L_{m} I_{d r}$

$\lambda_{q s}=L_{s} I_{q s}+L_{m} I_{q r}$

Similarly, the rotor flux linkage in the $d$-q reference frame is given as follows:

$\lambda_{d r}=L_{r} I_{d r}+L_{m} I_{d s}$

$\lambda_{q r}=L_{r} I_{q r}+L_{m} l_{q s}$

The self inductances of stator and rotor are given as follows: 


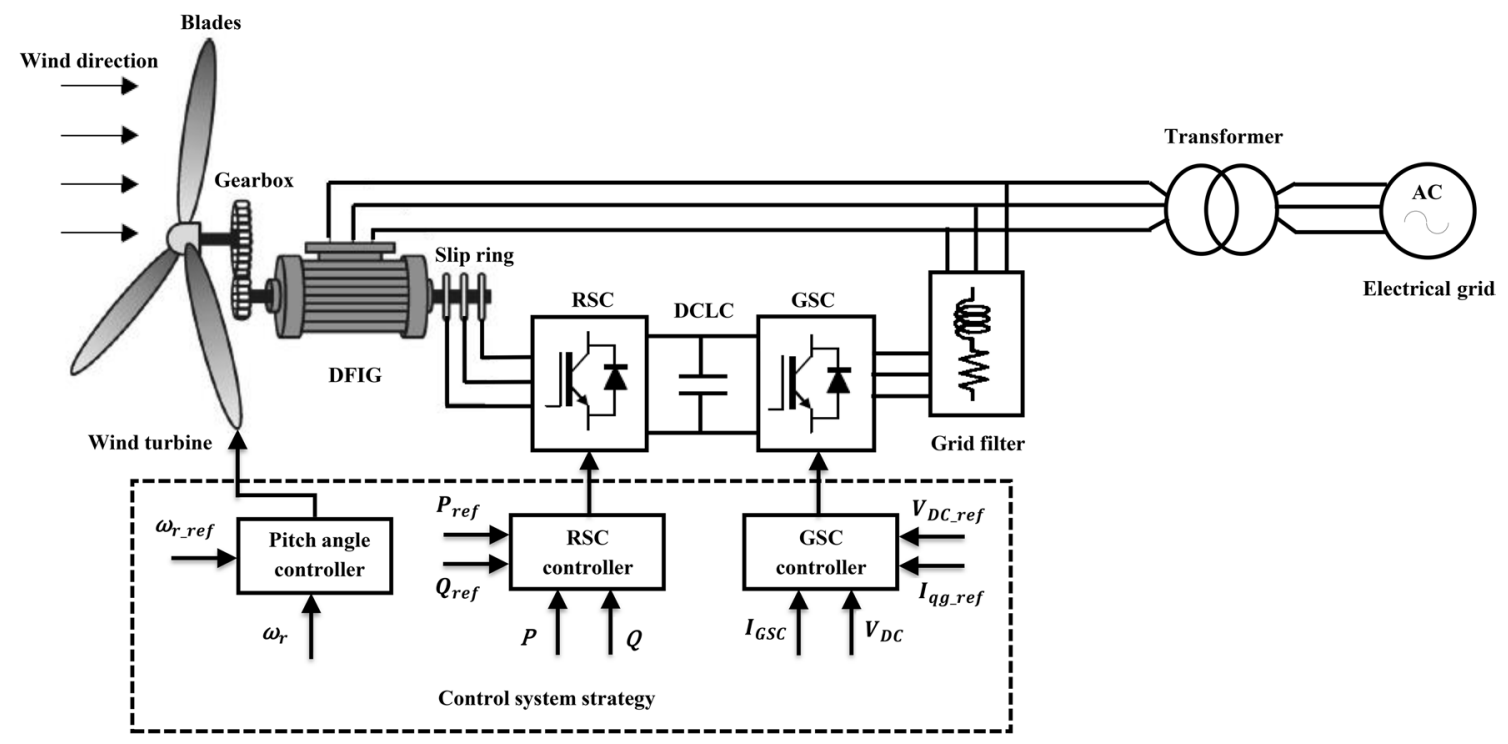

Fig. 1 General structure of DFIG wind turbine system

Fig. 2 Equivalent d-q representation circuits for DFIG a d-reference frame; $\mathbf{b}$ q-reference frame

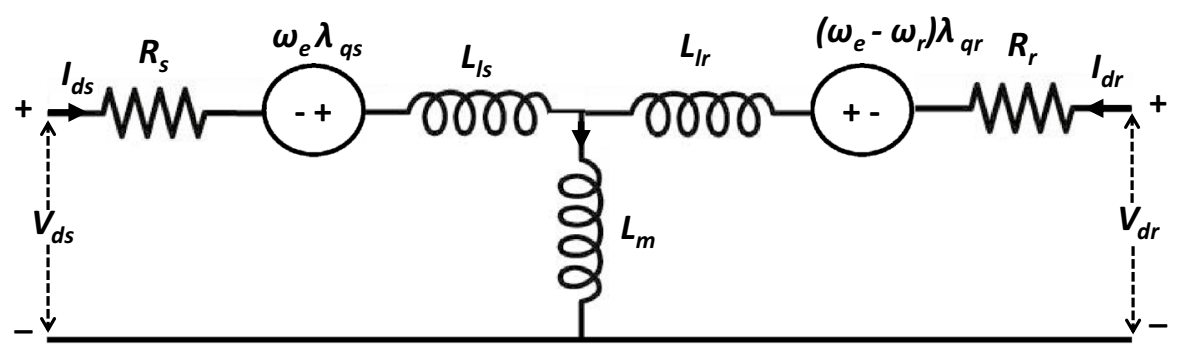

(a)

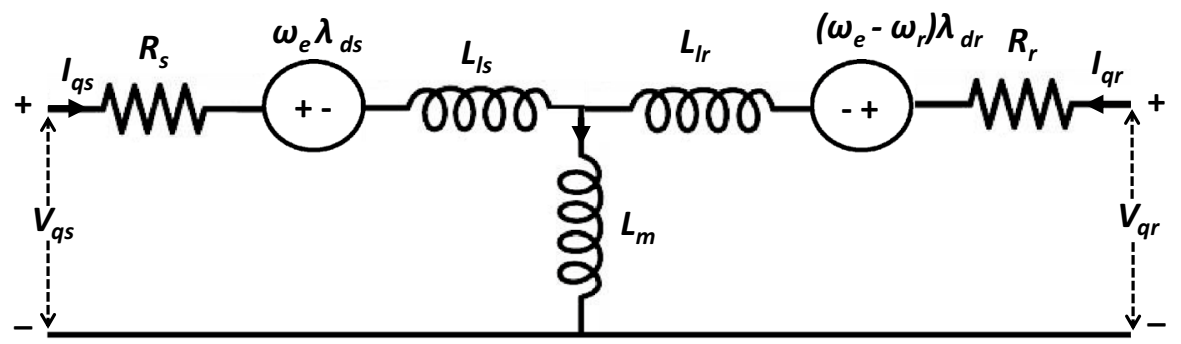

(b)
$L_{s}=L_{l s}+L_{m}$
$L_{r}=L_{l r}+L_{m}$

(9)

By substituting the stator and rotor flux linkages in the $\mathrm{d}$-q reference frame, thus the electromagnetic torque generated by DFIG can be expressed in (11) or (12) as follows:

$T_{e}=\lambda_{d s} I_{q s}-\lambda_{q s} I_{d s}$

$T_{e}=\lambda_{q r} I_{d r}-\lambda_{d r} I_{q r}$

The active and reactive power at the stator windings are defined as follows:
$P_{s}=V_{d s} I_{d s}+V_{q s} I_{q s}$

$Q_{s}=V_{q s} I_{d s}-V_{d s} I_{q s}$

The active and reactive power at the rotor windings are defined as follows:

$P_{r}=V_{d r} I_{d r}+V_{q r} I_{q r}$

$Q_{r}=V_{q r} I_{d r}-V_{d r} I_{q r}$

The total active and reactive power of stator-side and rotor-side can be expressed respectively as follows: 
$P=P_{s}+P_{r}$

$Q=Q_{s}+Q_{r}$

where $V_{d q s}$ is the $d$-q stator voltages, $V_{d q r}$ is the $d$-q rotor voltages, $I_{d q s}$ is the $d$-q stator currents, $I_{d q r}$ is the $d$-q rotor currents, $R_{s}$ is the stator resistance, $R_{r}$ is the rotor resistance, $L_{s}$ is the stator self inductance, $L_{r}$ is the rotor self inductance, $L_{/ s}$ is the stator leakage inductance, $L_{l r}$ is the rotor leakage inductance, $L_{m}$ is the magnetizing inductance, $\infty_{e}$ is the stator angular speed, $\omega_{r}$ is the rotor angular speed, $\lambda_{d q s}$ is the $d$-q stator flux linkage, $\lambda_{d q r}$ is the $d$-q rotor flux linkage, $T_{e}$ is the electromagnetic torque, $P_{s}$ is the stator active power, $Q_{s}$ is the stator reactive power, $P_{r}$ is the rotor active power, $Q_{r}$ is the rotor reactive power, $P$ is the total active power, and $Q$ is the total reactive power.

Generally, the overall control system strategy of DFIG wind turbine consists of pitch angle controller and electrical converter controllers using proportional integral structure. Firstly, the pitch angle controller is used to adjust the pitch angle of the wind turbine blades and protect the mechanical parts of turbine from damage, where it is activated due to wind speed increasing or fault occurrence. The pitch angle is calculated by the controller as follows:

$\beta=\left(\omega_{r_{-} r e f}-\omega_{r}\right) k_{P a}$

where $\omega_{r_{-} \text {ref }}$ is reference rotor speed of wind turbine, $\omega_{r}$ is measured rotor speed, and $k_{P a}$ is proportional gain for pitch angle controller.

Secondly, the electrical converter controllers are divided into RSC controller and GSC controller. The RSC controller is used to control the reactive power and active power via $V_{d r}$ and $V_{q r}$ respectively. The measured $\omega_{r}$ is processed through maximum power point tracking (MPPT) technique to generate the reference value of active power $P_{\text {ref }}$ On the other hand, the reference value of $Q_{\text {ref }}$ is given by the operator. The measured reactive power $Q$ and active power $P$ are compared with the desired values of $Q_{\text {ref }}$ and $P_{\text {ref }}$ to generate the reference signals $I_{d r_{-} r e f}$ and $I_{\text {qr_ref }}$ as follows:

$I_{d r_{r} \text { ref }}=\left(Q_{\text {ref }}-Q\right)\left(k_{\text {PVAR }}+\frac{k_{\text {IVAR }}}{S}\right)$

$I_{\text {r__ref }}=\left(P_{\text {ref }}-P\right)\left(k_{P P R}+\frac{k_{I P R}}{S}\right)$

where $I_{d r_{-} \text {ref }}$ is the d-component of reference current signal for RSC, $k_{P V A R}$ and $k_{\text {IVAR }}$ are proportional integral gains for reactive power controller, $I_{q r_{-} r e f}$ is the q-component of reference current signal for RSC, $k_{P P R}$ and $k_{I P R}$ are proportional integral gains for active power controller, and $S$ is the Laplace operator. The measured rotor-side current $I_{\text {RSC }}$ is transformed into $I_{d r}$ and $I_{q r}$ then compared with the reference signals $I_{d r_{-} \text {ref }}$ and $I_{q r_{-} \text {ref }}$ to generate error signals respectively. These error signals are passing through two proportional integral controllers to generate the voltage signal references $V_{d r}$ and $V_{q r}$ as follows:

$V_{d r}=\left(I_{d r \_r e f}-I_{d r}\right)\left(k_{P R}+\frac{k_{l R}}{S}\right)$

$V_{q r}=\left(I_{q r_{-} \text {ref }}-I_{q r}\right)\left(k_{P R}+\frac{k_{l R}}{S}\right)$

where $k_{P R}$ and $k_{I R}$ are proportional integral gains for rotorside current controller. The voltage signals of $V_{d r}$ and $V_{q r}$ are transformed to form a signal of $V_{r}$ which is used by the pulse width modulation (PWM) switching signal module to generate the control signals of insulated gate bipolar transistors (IGBTs) to drive the RSC for controlling the reactive and active power.

The GSC controller is used to control the DCLC voltage that connected between RSC and GSC, also it regulates the reactive power between GSC and electrical grid. The measured values of the DC-link voltage $V_{D C}$ is compared with its reference value $V_{D C_{\text {rref }}}$ to generate the error signal, where it is passing through the proportional integral controller to generate the reference signal $I_{d g_{-} \text {ref }}$ as follows:

$I_{d g_{-} \text {ref }}=\left(V_{D C \_ \text {ref }}-V_{D C}\right)\left(k_{P D C}+\frac{k_{I D C}}{S}\right)$

where $k_{P D C}$ and $k_{I D C}$ are proportional integral gains for DCLC voltage controller. On the other hand, the reference value of $I_{\text {qg_ref }}$ is given by the operator. The measured grid-side current $I_{G S C}$ is transformed into $I_{d g}$ and $I_{q g}$ then compared with the reference signals $I_{d g \_r e f}$ and $I_{\text {gg_ref }}$ to generate error signals respectively. These error signals are passing through two proportional integral controllers to generate the voltage signal references $V_{d g}$ and $V_{q g}$ as follows:

$V_{d g}=\left(I_{d g_{\_} r e f}-I_{d g}\right)\left(k_{P g}+\frac{k_{l g}}{S}\right)$

$V_{q g}=\left(I_{q g_{\_} r e f}-I_{q g}\right)\left(k_{P g}+\frac{k_{l g}}{S}\right)$

where $k_{p g}$ and $k_{l g}$ are proportional integral gains of gridside current controller. The voltage signals of $V_{d g}$ and $V_{q g}$ are transformed to form a signal of $V_{g}$ which is used by the PWM module to generate the control signals of IGBTs to drive the GSC for controlling the DCLC voltage and reactive power. 


\section{Egyptian LVRT grid code}

The wind turbine generators must be stay in service during fault occurrence for a specific voltage value within certain time according to LVRT grid code $[1,13]$. Figure 3 illustrates the Egyptian LVRT grid code for wind turbines connected to electrical grid. During voltage dip occurrence, the voltage level and its maximum duration are specified through the grid code. This grid code states that, the wind turbines must not be disconnected from the grid in the event of $100 \%$ voltage dip caused by a severe fault for a duration time equal to or less than $150 \mathrm{~ms}$, where the maximum duration time to restore the voltage is $3 \mathrm{~s}$. The wind turbine generators are not allowed to be disconnected from the electrical grid during faults when voltage level is located above LVRT curve, while the wind turbine generators are allowed to be disconnected from the grid when voltage level is located under LVRT curve.

\section{Design of proposed protection technique}

The design of proposed protection technique consists of two approaches, where the first approach is ANFIS fault detector and the second approach is implementation of Egyptian LVRT grid code. The design and operation scenario of these approaches are described in the following subsections.

\subsection{ANFIS fault detector}

The ANFIS fault detector consists of five layers, where it has two input signals $\left(V_{a b c}, l_{a b c}\right)$ and one output signal as shown in Fig. 4. Layer 1 is a fuzzification layer which uses to transform the measured input values into fuzzy inputs. Layer 2 is a rule layer labeled by $\pi$ which presents the relationships between inputs and output signals by using IF-THEN rules. Layer 3 is a normalization layer labeled by $\mathrm{N}$ which calculates the normalized weights or normalized firing strengths by using the ratio of firing strength rule to sum of all firing strengths rules. Layer 4 is a defuzzification layer which uses to transform the fuzzy results into a crisp output. Finally, the layer 5 is a summation layer labeled by $\Sigma$ which computes the final output by summing of all incoming signals. The ANFIS fault detector is trained to tune the parameters via optimization algorithm in order to minimize the error between ANFIS output and actual output for a given inputs and output data pairs of training patterns. The trained ANFIS parameters are selected as follows; three Gaussian membership functions for inputs, constant type for output, zero error tolerance, 300 epochs, grid partitions, and hybrid optimization algorithm. As indicated in Fig. 4, the circle indicates a non-adaptive node and the square indicates an adaptive node, $A_{j}$ and $B_{k}$ are the linguistic labels, $w_{i}$ is the output of second layer, $\bar{w}_{i}$ is the output of third layer, $z_{i}$ is the output within the fuzzy region specified by the fuzzy rule, $i=(1,2, \ldots, m \times n)$ is the number of rules, $j=(1,2, \ldots, m)$, and $k=(1,2, \ldots, n)$ are the number of membership functions.

\subsection{Implementation of Egyptian LVRT grid code}

The implementation of Egyptian LVRT grid code curve is designed by dividing it into three zones according to the variation of voltage with time as shown in Fig. 5a. Zone 1 starts from instant of fault occurrence to a minimum time $\left(t_{\min }\right)$ of $150 \mathrm{~ms}$ and the voltage level at wind turbine terminal is equal to or greater than minimum voltage $\left(V_{\min }\right)$ of $0 \mathrm{pu}$. Zone 2 starts from $t_{\min }$ of $150 \mathrm{~ms}$ to recovery time $\left(t_{\text {rec }}\right)$ of $3 \mathrm{~s}$, where the voltage level is defined as a ramp growth of recovery voltage from $V_{\min }$ of 0 pu to recovery voltage $\left(V_{\text {rec }}\right)$ of $0.85 \mathrm{pu}$. Taking into account, the programming setting of zone 2 is implemented in discrete time
Fig. 3 Egyptian LVRT grid code for wind turbine generators

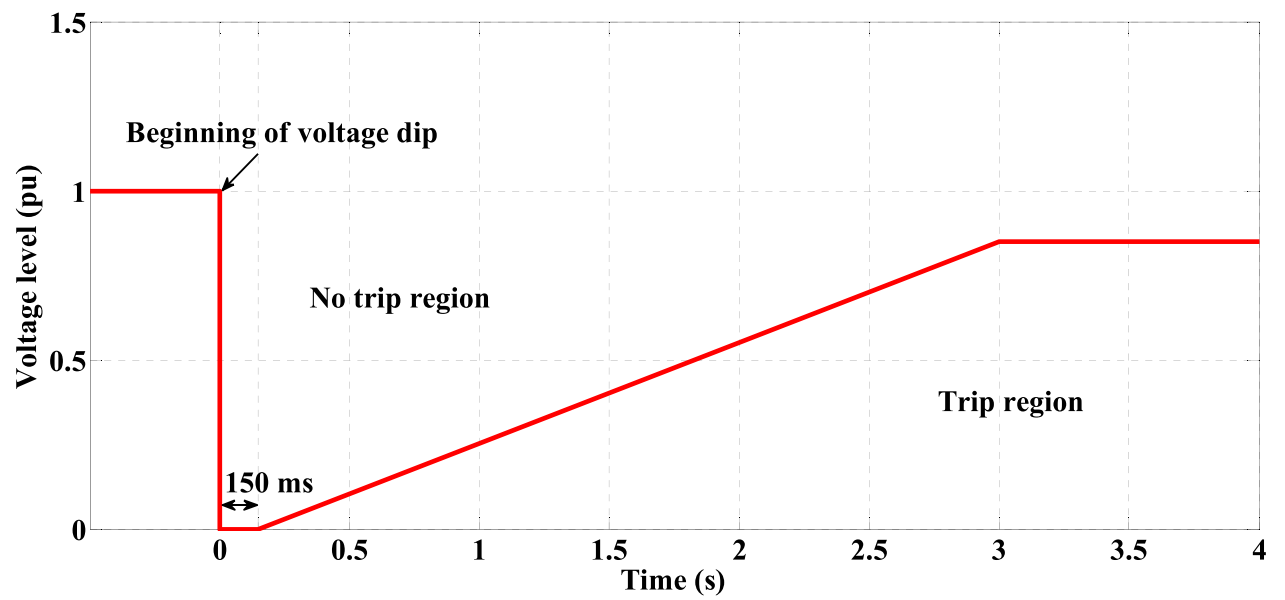

SN Applied Sciences 


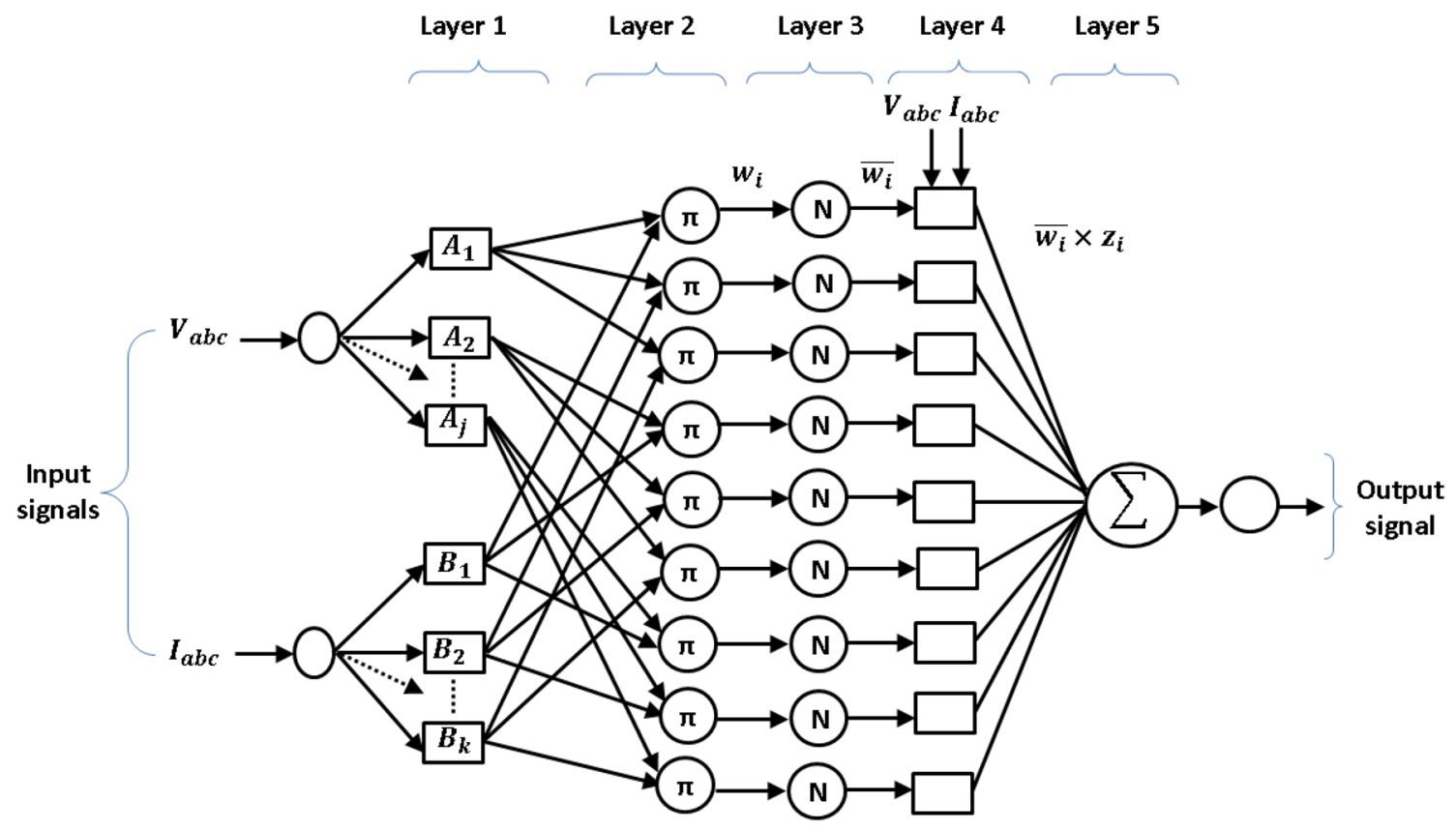

Fig. 4 ANFIS fault detector approach

Fig. 5 Implementation of Egyptian LVRT grid code a curve zones; $\mathbf{b}$ programmed curve zones

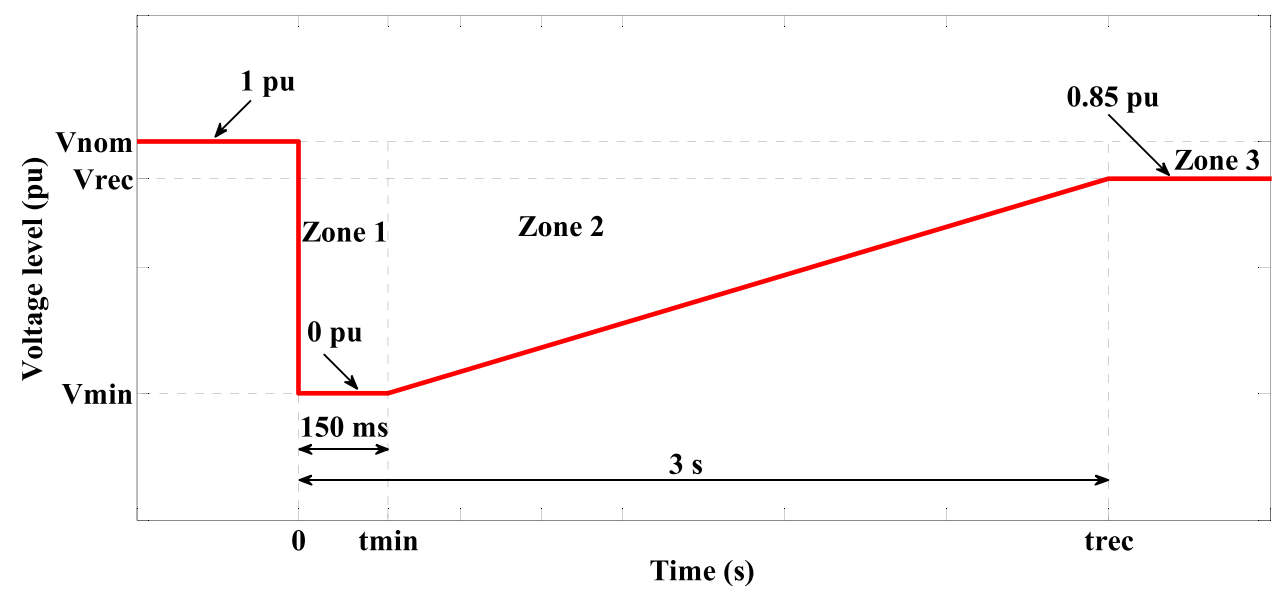

(a)

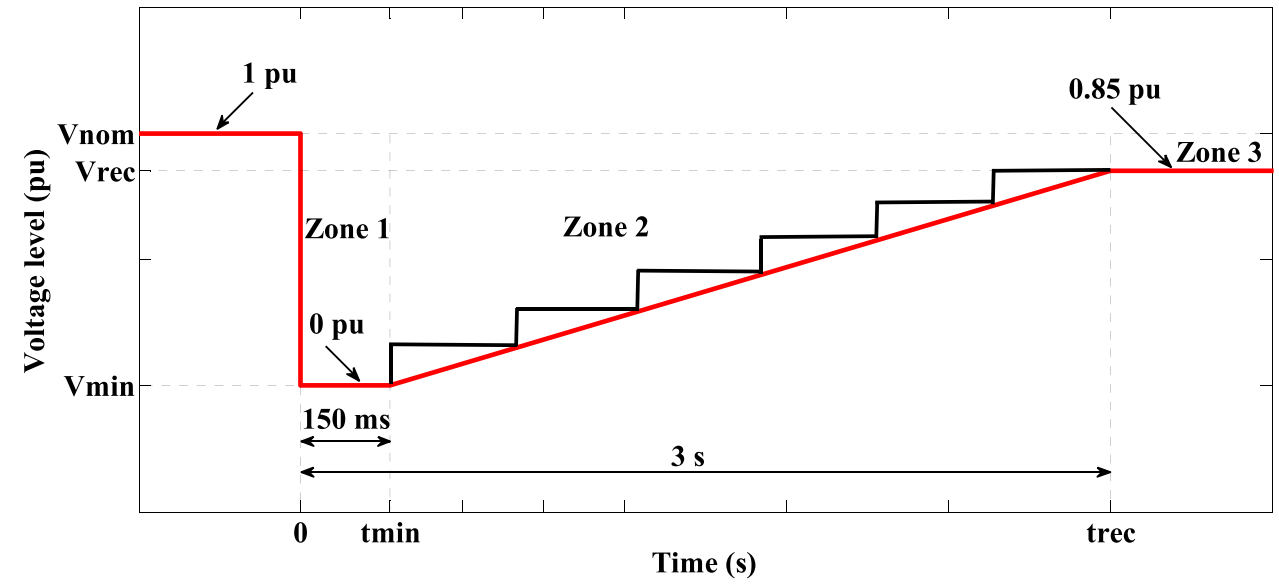

(b) 
intervals not in continuous ramp growth interval as shown in Fig. 5b. Zone 3 starts after $t_{\text {rec }}$ of $3 \mathrm{~s}$, where the voltage level is equal to or greater than $V_{\text {rec }}$ of $0.85 \mathrm{pu}$. It is clear that, the wind turbine generators can stay in service if the voltage is decreased to 0 pu due to occurrence of severe fault for a duration time less than or equal to $150 \mathrm{~ms}$. Otherwise, the wind turbine generators which located in faulted area should be disconnected from service if the measured voltage at its terminal falls to zero for a duration time greater than $150 \mathrm{~ms}$. On the other hand, the wind turbine generator can stay in service if the measured voltage is greater than zero for specified time, where this specified time depends on the slope of LVRT curve from $t_{\min }$ of $150 \mathrm{~ms}$ to $t_{\text {rec }}$ of $3 \mathrm{~s}$.

As shown in Fig. 6, the operation scenario of proposed protection technique is divided into two main approaches, the first one is a fault detector based on ANFIS networks, where the ANFIS networks is trained by using measured data in cases of normal and abnormal conditions to get accurate fault detector decision. The output decision signal of ANFIS fault detector is ' 0 ' in case of un-faulted conditions and ' 1 ' in case of faulted conditions for the studied system. Therefore, the first approach is used to discriminate between faulted and un-faulted conditions during voltage dips. Taking into account, the IEEE Standard 1159-1995 shows that, the term of sag is defined as a decrease in voltage magnitude to a value varied between 0.1 and $0.9 \mathrm{pu}$, for a time period varied between 0.5 cycles to $1 \mathrm{~min}$ [48]. Therefore, the wind farm generators can stay in service during voltage sag in case of un-faulted conditions based on output signal of the first approach. The second approach is designed to compare the measured voltage $V_{a b c}$ at the terminal of protected wind turbine generator with the programmed Egyptian LVRT grid code curve. The generated decision of the second approach depends on the measured voltage dip value at wind turbine bus and its duration time. The output decision signal of the second approach is ' 0 ' if the measured voltage value is located in no trip region above LVRT curve and ' 1 ' if the measured value is located in trip region under LVRT curve. Finally, the proposed protection technique trips the circuit breaker (CB) of wind turbine generator during fault occurrence just when the fault is detected and the measured voltage value at wind turbine terminal located in trip region only. The flowchart of proposed technique based on fault detection and Egyptian LVRT grid code is illustrated in Fig. 7. A simulation model of 200 MW Gabal El-Zayt wind farm is introduced in the following section to investigate the accuracy of the proposed protection technique at different conditions such as fault duration

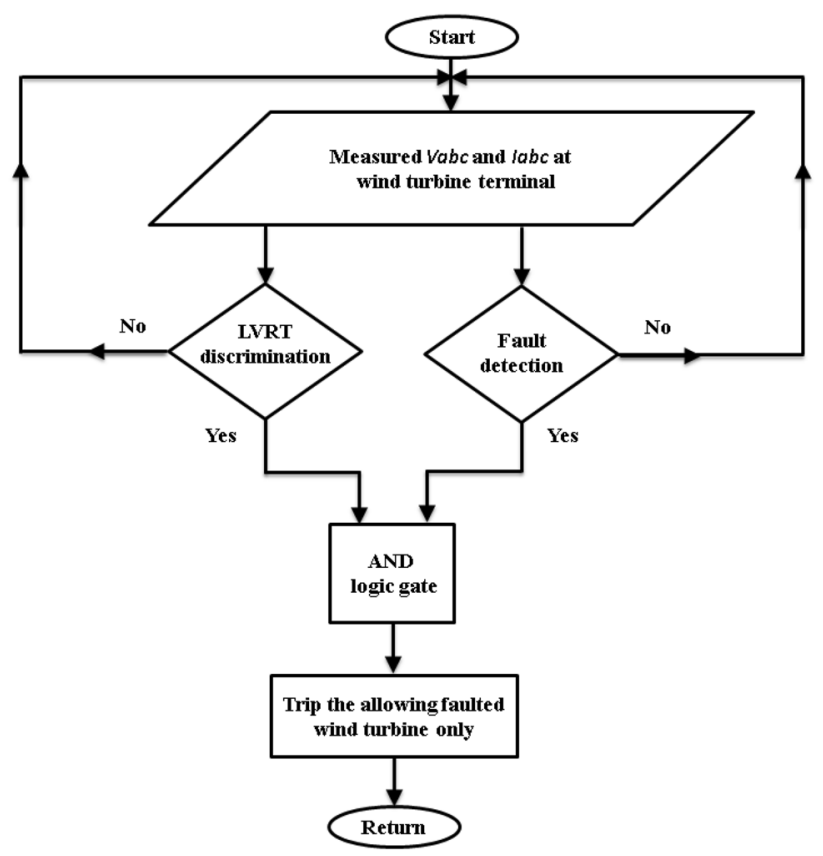

Fig. 7 Flowchart of the proposed protection technique
Fig. 6 Flow diagram of the proposed protection technique

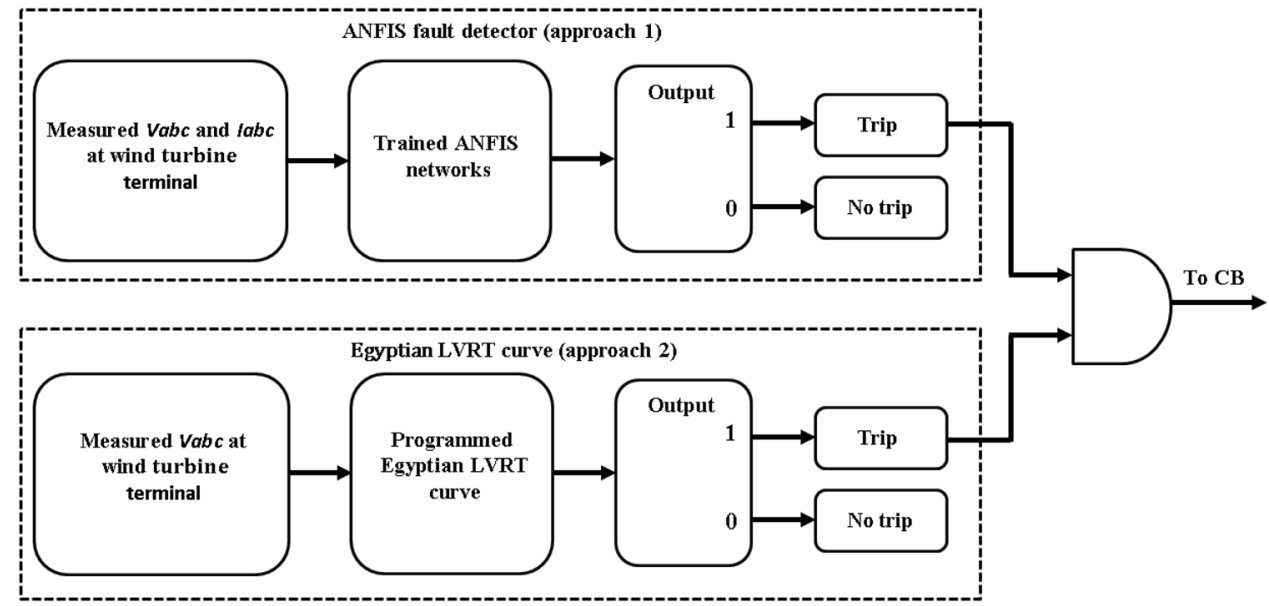

SN Applied Sciences A SPRINGER NATURE journal 
for different fault types, internal and external fault locations, grid voltage sag, and different ground transition resistances.

\section{Configuration of studied wind farm}

The configuration of studied 200 MW Gabal El-Zayt wind farm is shown in Fig. 8. The studied wind farm consists of 100 DFIG wind turbines with a capacity of $2 \mathrm{MW}$ for each of them $[2,4]$. The simulated wind turbine generators are divided into four groups, where the generated power of each of them is $42 \mathrm{MW}, 54 \mathrm{MW}, 52 \mathrm{MW}$, and $52 \mathrm{MW}$ respectively. Each wind turbine generator is coupled with step-up transformer $(0.69 / 22 \mathrm{kV})$, where all generators are connected to electrical grid via 2 step-up threewinding transformers (22/22/220 kV). Every two groups are connected to a separated step-up three-winding transformer, then the total generated power is collected at wind farm PCC bus and delivered to $220 \mathrm{kV}$ electrical grid via a $50 \mathrm{~km}$ transmission line from Gabal El-Zayt wind farm to Ras Gharib. Each wind turbines group is protected by a separated one proposed protection technique based on measured voltage and current values at each group terminals. The main parameters of studied wind farm components such as DFIGs, transformers, feeders, and transmission line for studied wind farm are illustrated in Table 1.

\section{Simulation results and analysis}

In this section, different scenarios are studied to investigate the stability of Gabal EL-Zayt wind farm equipped with proposed protection technique. The operation mechanism of proposed protection technique is designed to trip the $C B$ of wind turbine generator during faults just when the fault is detected via ANFIS approach and the measured voltage value at wind turbine terminal located in trip region of LVRT grid code. Therefore, if the output decision signals of the two approaches are ' 1 ', the wind turbine generator will be disconnected from grid. Otherwise, if the output decision signals of the two approaches or one of them are ' 0 ', the wind turbine generator will be stay connected to grid. The studied wind farm is operated at a wind speed of $12 \mathrm{~m} / \mathrm{s}$ and the total generated active power measured at PCC is $180.4 \mathrm{MW}$. In the following subsections, the impacts of fault duration, fault type, internal and external fault locations, grid voltage sag, and different ground transition resistance values are studied.

\subsection{Impacts of different fault durations and fault types}

In this subsection, the impacts of fault duration for different fault types such as single-phase to ground, doublephase to ground, and three-phase to ground faults are studied. Also, the different fault durations such as $150 \mathrm{~ms}$, $1 \mathrm{~s}$ and $3 \mathrm{~s}$ are studied to evaluate the performance of proposed protection technique.

\subsubsection{Impact of single-phase to ground fault}

The impact of single-phase to ground fault on the performance of proposed technique is studied when the fault occurs on phase ' $a$ ' at wind turbine generator group 1 feeder. Figure 9 shows the variations of measured values at group 1 bus and at PCC bus of studied wind farm. Figure 9a shows the variation of voltage at group 1 bus of faulted wind turbine generators, it can be observed that, the measured voltage value locates above the Egyptian LVRT curve and it has not obvious variation. Also, the measured voltage at PCC bus of wind farm is not affected by different duration times of single-phase to ground fault as is shown in Fig. 9b. It is clear that, the measured active power at group 1 bus of faulted wind turbine generators and at PCC bus of wind farm has very little variations as shown in Fig. 9c, d. Moreover, the proposed protection technique detects the occurrence of single-phase to ground fault and not isolates the wind turbine generators of group 1, because the measured voltage value at group 1 bus locates in no trip region.

\subsubsection{Impact of double-phase to ground fault}

The impact of double-phase to ground fault on the performance of proposed technique is studied when the fault occurs on phase ' $a$ ' and phase ' $b$ ' at wind turbine generator group 1 feeder. As shown in Fig. 10a, the measured voltage values of group 1 bus are located above the LVRT curve in cases of fault durations of $150 \mathrm{~ms}$ and $1 \mathrm{~s}$, therefore the proposed protection technique should not isolate the wind turbine generators of group 1. On the other hand, when the fault duration is $3 \mathrm{~s}$, the measured voltage value falls under LVRT curve, then the proposed protection technique isolates the wind turbine generators of group 1 . Thus, in case of $3 \mathrm{~s}$ fault duration the proposed protection technique isolates the faulted wind turbines because the double-phase to ground fault is detected through fault detector of approach 1 and the fault duration is not fulfilling the LVRT curve through approach 2 of the proposed technique. As shown in Fig. 10b, the measured voltage value at PCC bus falls to 0.9383 pu during the fault period and returns to its normal value after fault clearance. The 
Group $1(21 \times 2 \mathrm{MW})$

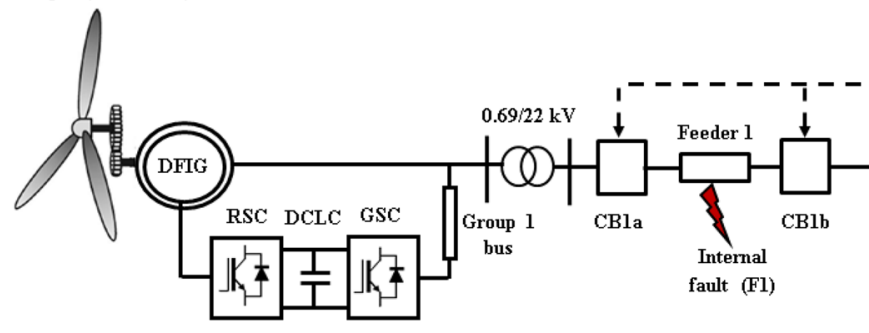

Group $2(27 \times 2 \mathrm{MW})$

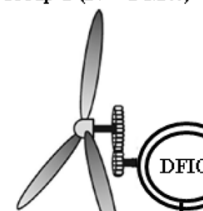

DFIG

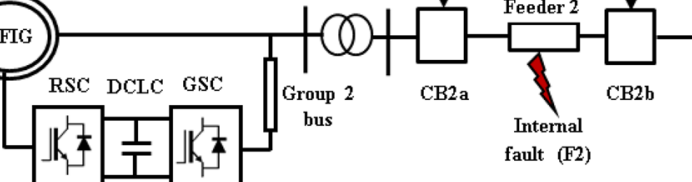

Group $3(26 \times 2 \mathrm{MW})$
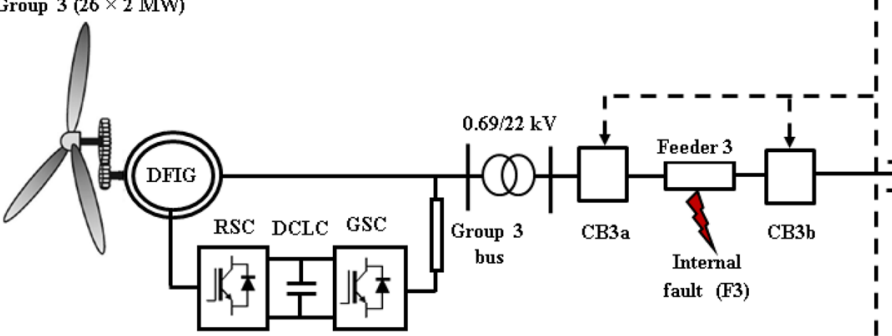

CB3a

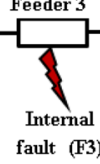

Group $4(26 \times 2 \mathrm{MW})$
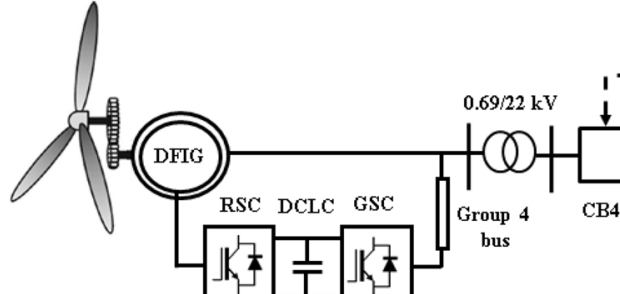

fault (13)
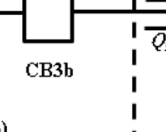

\section{I $P_{1}$}

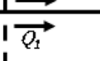


Table 1 The main parameters of simulated studied system

\begin{tabular}{|c|c|c|}
\hline \multirow[t]{2}{*}{ System description } & \multicolumn{2}{|l|}{ Parameters and values } \\
\hline & Parameters & Values \\
\hline \multirow[t]{7}{*}{ DFIG } & Rated power & $2 \mathrm{MW}$ \\
\hline & Rated voltage & $690 \mathrm{~V}$ \\
\hline & Stator resistance & $0.00706 \mathrm{pu}$ \\
\hline & Stator leakage inductance & $0.1709 \mathrm{pu}$ \\
\hline & Rotor resistance & $0.005 \mathrm{pu}$ \\
\hline & Rotor leakage inductance & $0.155 \mathrm{pu}$ \\
\hline & Mutual inductance & $2.9 \mathrm{pu}$ \\
\hline \multirow[t]{6}{*}{ Transmission line } & Zero sequence resistance & $0.4129 \Omega / \mathrm{km}$ \\
\hline & Zero sequence inductance & $0.00331 \mathrm{H} / \mathrm{km}$ \\
\hline & Zero sequence capacitance & $5.01 \exp -9 \mathrm{~F} / \mathrm{km}$ \\
\hline & Positive sequence resistance & $0.11529 \Omega / \mathrm{km}$ \\
\hline & Positive sequence inductance & $0.001049 \mathrm{H} / \mathrm{km}$ \\
\hline & Positive sequence capacitance & 11.329exp-9 F/km \\
\hline \multirow[t]{4}{*}{ Feeders } & Zero sequence resistance & $0.3963 \Omega / \mathrm{km}$ \\
\hline & Zero sequence inductance & $0.00273 \mathrm{H} / \mathrm{km}$ \\
\hline & Positive sequence resistance & $0.1153 \Omega / \mathrm{km}$ \\
\hline & Positive sequence inductance & $0.00105 \mathrm{H} / \mathrm{km}$ \\
\hline \multirow[t]{3}{*}{ Wind turbines transformers } & Turns ratio & $0.69 \mathrm{kV} / 22 \mathrm{kV}$ \\
\hline & Resistance & $0.0081 \mathrm{pu}$ \\
\hline & Reactance & $0.0453 \mathrm{pu}$ \\
\hline \multirow[t]{3}{*}{ PCC bus transformers } & Turns ratio & $22 \mathrm{kV} / 22 \mathrm{kV} / 220 \mathrm{kV}$ \\
\hline & Resistance & $0.0051 \mathrm{pu}$ \\
\hline & Reactance & $0.065 \mathrm{pu}$ \\
\hline
\end{tabular}

variation of generated active power of faulted group 1 is illustrated in Fig. 10c. It is clear that, the measured active power at group 1 bus is decreased to $26.65 \mathrm{MW}$ during fault periods of $150 \mathrm{~ms}$ and $1 \mathrm{~s}$, then returns to its normal value after fault clearance. Otherwise, in case of $3 \mathrm{~s}$ fault duration, it is decreased to $26.65 \mathrm{MW}$ for a certain time and then it falls to $0 \mathrm{MW}$ where the wind turbine generators of group 1 are isolated due opening the $C B$, then it returns to its normal value after fault clearance due to reclosing the $C B$ via the proposed technique. The variation of generated active power at wind farm PCC bus is illustrated in Fig. 10d. It is clear that, the measured active power at PCC bus is decreased to $132.6 \mathrm{MW}$ during fault periods of $150 \mathrm{~ms}$ and $1 \mathrm{~s}$, then returns to its normal value after fault clearance, while in case of $3 \mathrm{~s}$ fault duration, it is decreased to $132.6 \mathrm{MW}$ during a certain time and it increases to $142.4 \mathrm{MW}$, where the wind turbine generators of group 1 are isolated, that means the $C B$ is opened via the proposed technique, then returns to its normal value after fault clearance.

\subsubsection{Impact of three-phase to ground fault}

The impact of three-phase to ground fault on the performance of proposed technique is studied when the fault occurs at wind turbine generator group 1 feeder. As shown in Fig. 11a, in case of fault duration of $150 \mathrm{~ms}$, the measured voltage values of group 1 bus are located above the LVRT curve and the fault duration does not exceed $150 \mathrm{~ms}$, therefore the proposed protection technique should not isolate the wind turbine generators of group 1. On the other hand, when the fault durations are $1 \mathrm{~s}$ and $3 \mathrm{~s}$, the measured voltage value falls under LVRT curve, therefore the proposed protection technique isolates the wind turbine generators of group 1 . As shown in Fig. $11 \mathrm{~b}$ the measured voltage value at PCC bus falls to 0.8712 pu during fault period and returns to its normal value after fault clearance. The variation of generated active power of faulted group 1 is illustrated in Fig. 11c. It is clear that, the measured active power at group 1 bus is decreased to $0 \mathrm{MW}$ during all studied fault periods, then returns to its normal value after fault clearance. The measured active power at PCC bus of wind farm is decreased to $70.44 \mathrm{MW}$ for all studied fault periods as illustrated in Fig. $11 \mathrm{~d}$. The active power returns to steady state value after fault clearance in case of $150 \mathrm{~ms}$ fault duration, while it returns to $142.4 \mathrm{MW}$ in cases of $1 \mathrm{~s}$ and $3 \mathrm{~s}$ fault periods due to isolating of wind turbine generators of group 1 during fault periods and returns to steady state value after fault clearance. 
Fig. 9 Variations of measured values in case of different fault durations during single-phase to ground fault a voltage at group 1 bus; $\mathbf{b}$ voltage at PCC bus; $c$ active power at group 1 bus; $\mathbf{d}$ active power at PCC bus

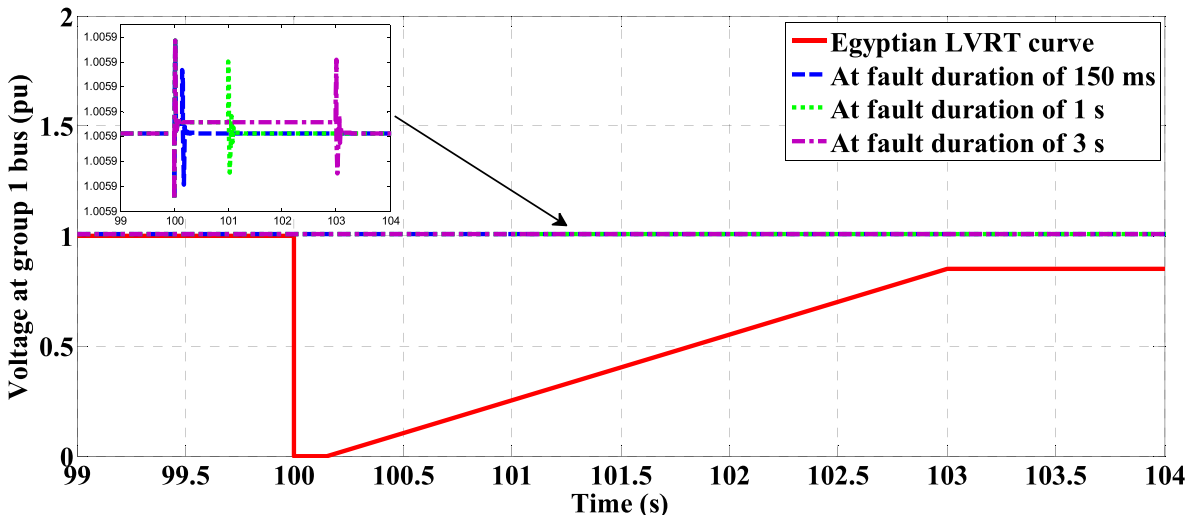

(a)

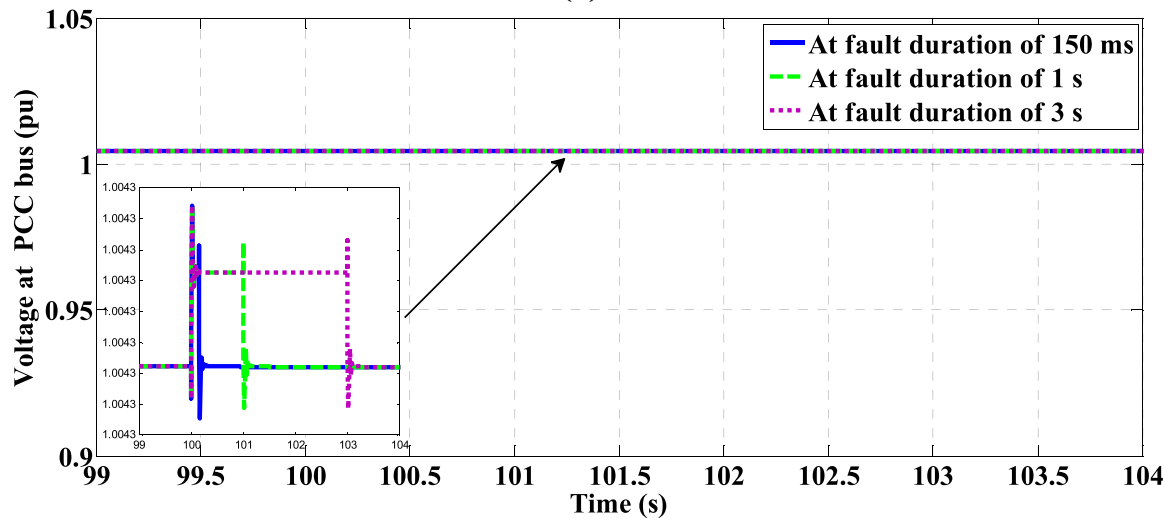

(b)

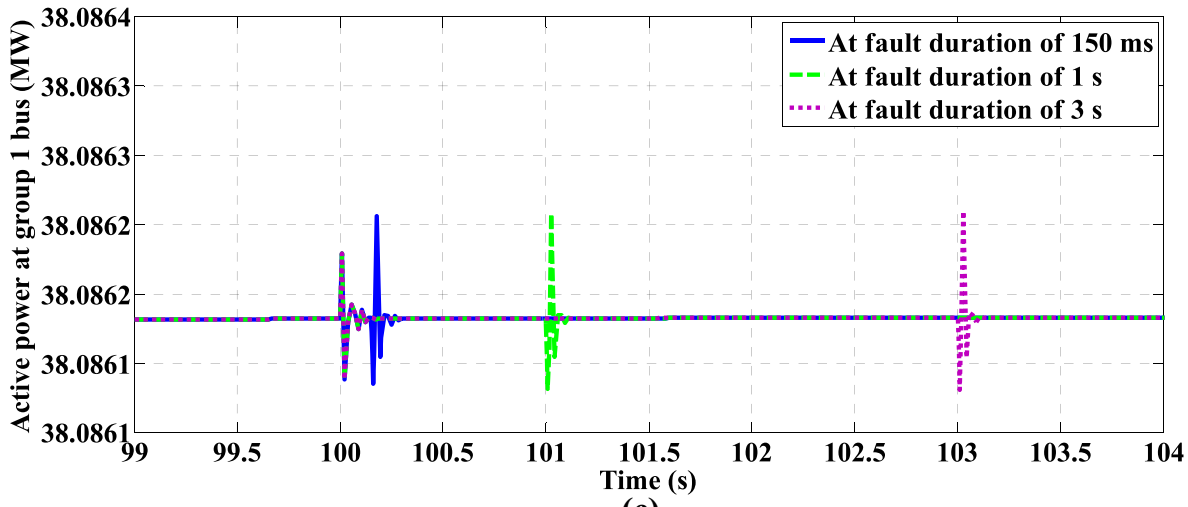

(c)

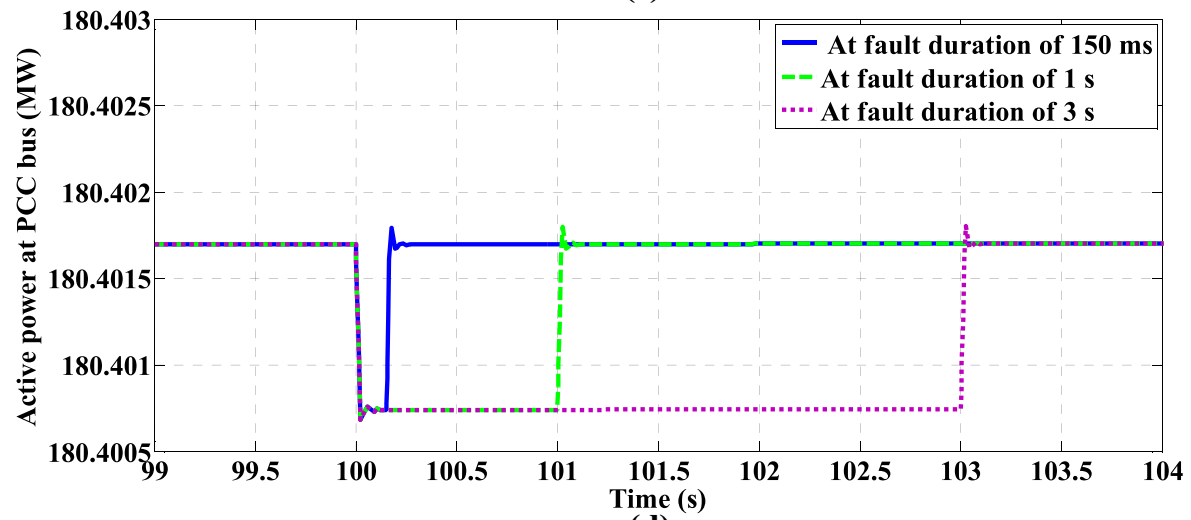

(d) 
Fig. 10 Variations of measured values in case of different fault durations during double-phase to ground fault a voltage at group 1 bus; $\mathbf{b}$ voltage at PCC bus; $c$ active power at group 1 bus; $\mathbf{d}$ active power at PCC bus

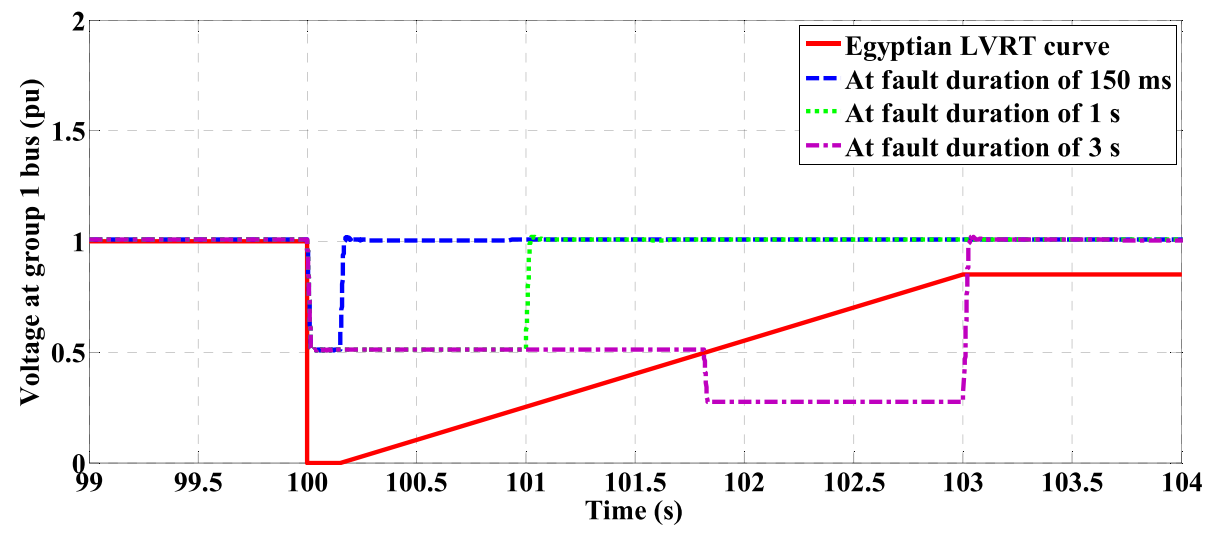

(a)

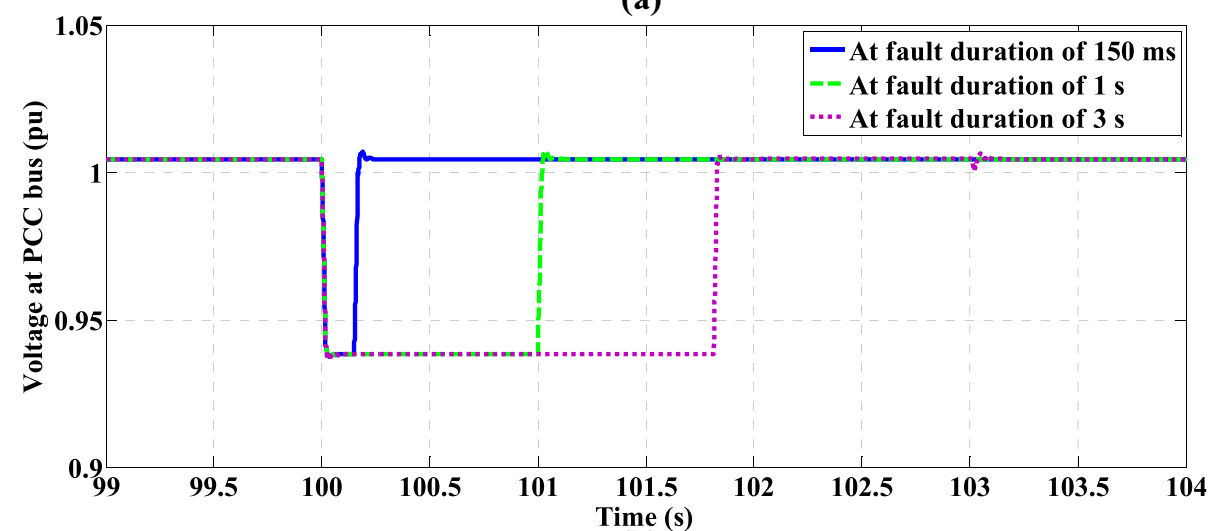

(b)

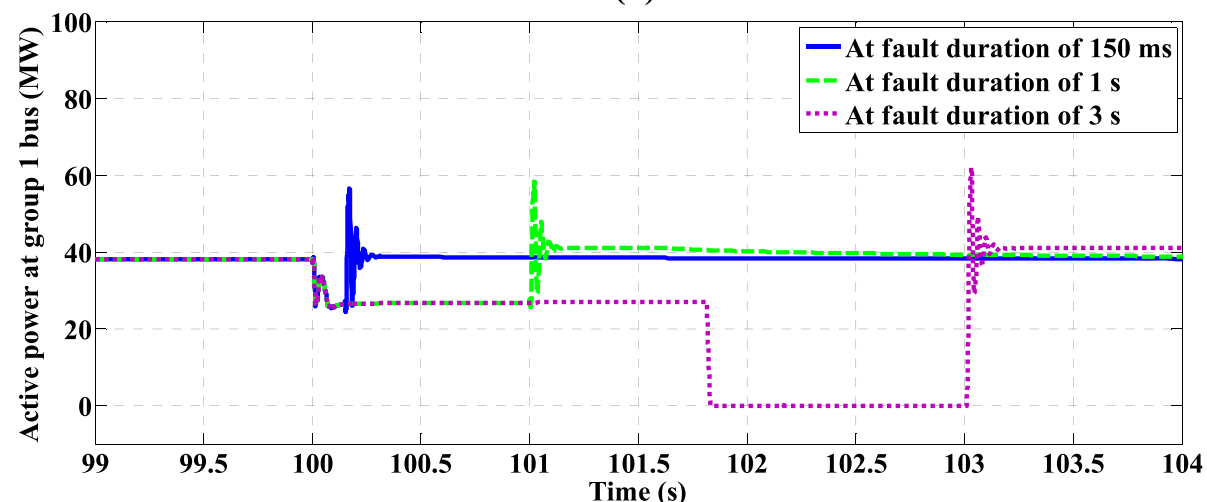

(c)

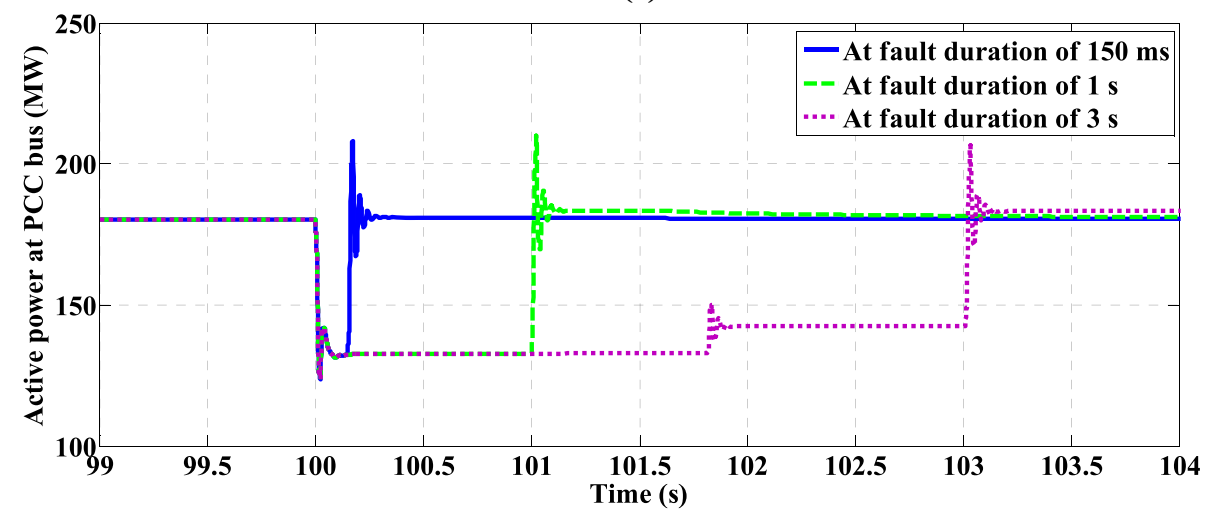

(d) 
Fig. 11 Variations of measured values in case of different fault durations during three-phase to ground fault a voltage at group 1 bus; $\mathbf{b}$ voltage at PCC bus; $c$ active power at group 1 bus; $\mathbf{d}$ active power at PCC bus

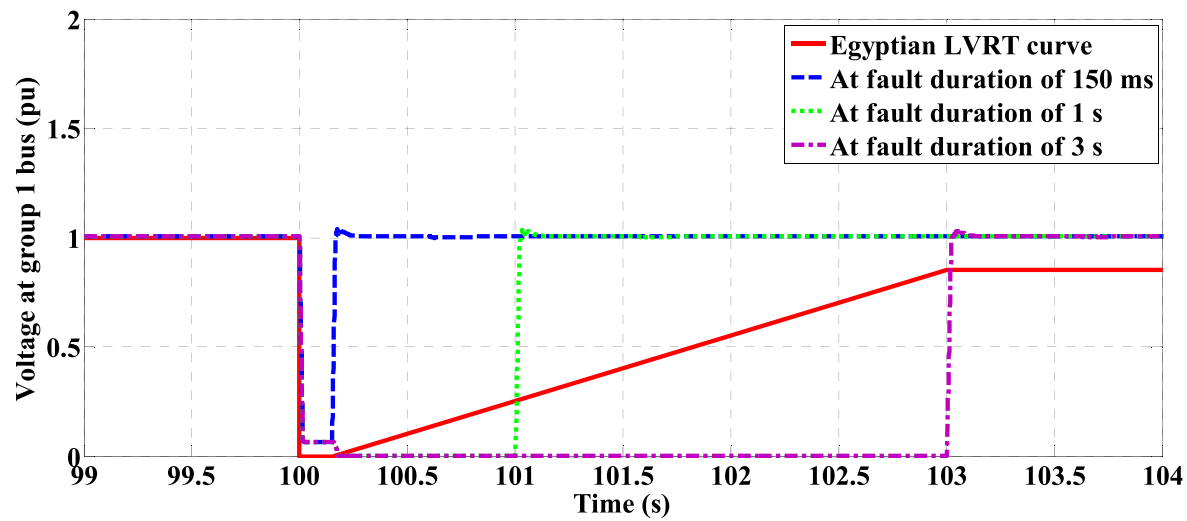

(a)

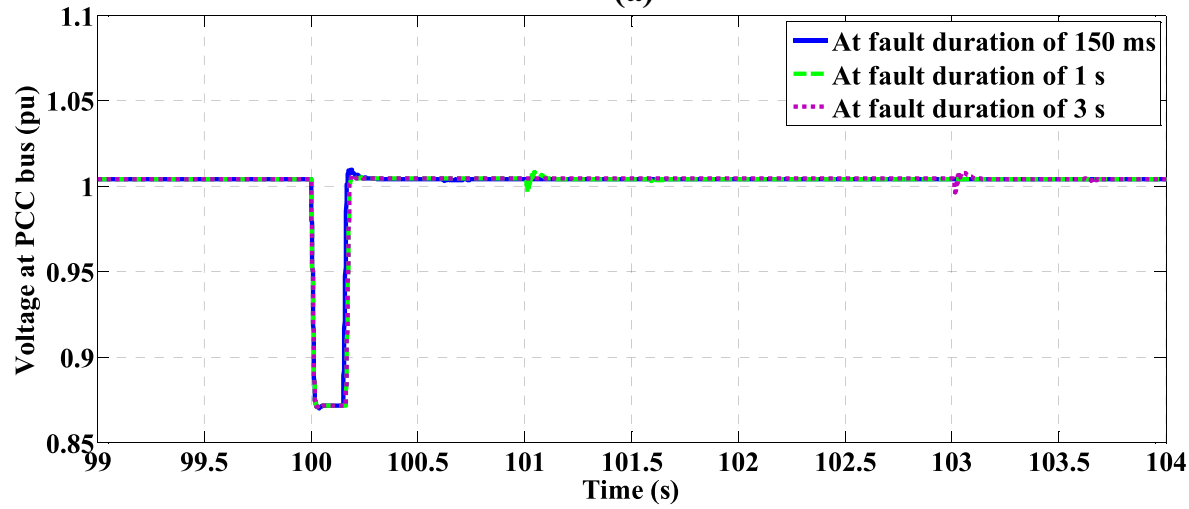

(b)

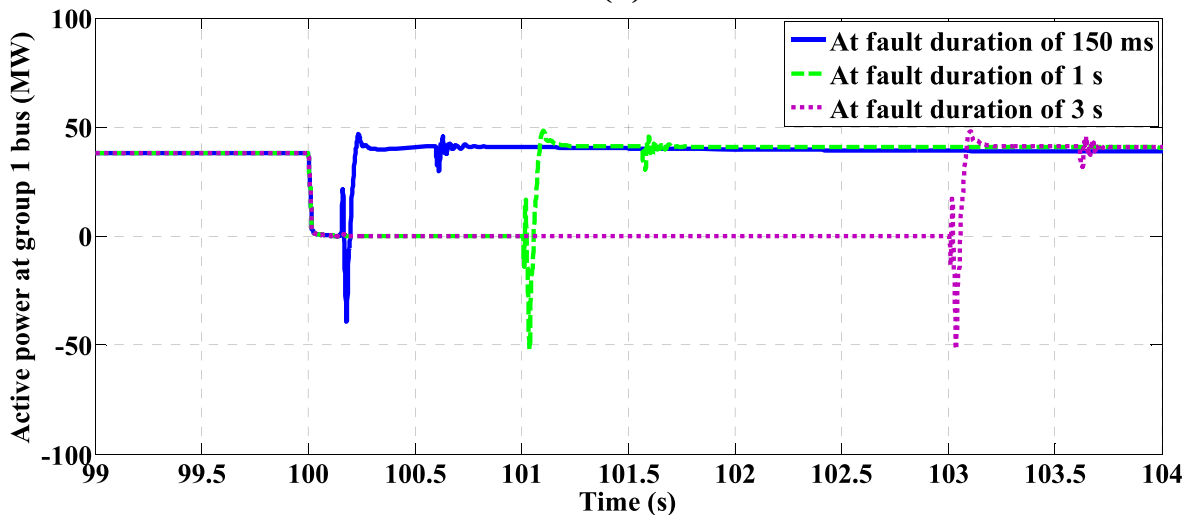

(c)

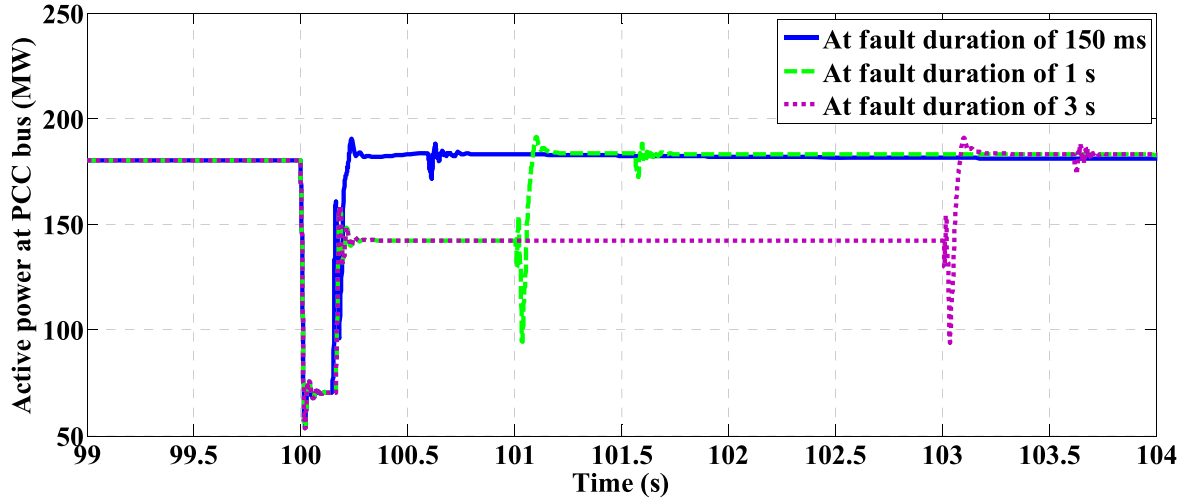

(d) 


\subsection{Impacts of internal and external faults}

In this subsection, a comparison between the behaviours of studied system in cases of internal and external faults is performed during occurrence of three-phase to ground fault for $1 \mathrm{~s}$ duration time. The studied fault occurs at group 1 as internal fault, while it occurs at the PCC bus of wind farm as external fault. Figure $12 a$, b show the variation of measured voltage at group 1 bus and at wind farm PCC bus respectively. The proposed technique detects the fault occurrence in cases of internal and external faults then isolates the faulted area in case of internal fault, while it isolates all wind farm generators in case of external fault, where the fault duration exceeds $150 \mathrm{~ms}$. The measured voltage at PCC bus decreases to $0.87 \mathrm{pu}$ in case of internal fault and decreases to 0 pu in case of external fault. As shown in Fig. 12c, the generated active power of group 1 decreases to $0 \mathrm{MW}$, where its generators are isolated during internal and external fault periods by the proposed technique, then the generated power returns to steady state value after fault clearance. The variation of wind farm active power which measured at PCC bus is shown in Fig. $12 \mathrm{~d}$. The generated active power at PCC bus is decreased to $70.44 \mathrm{MW}$ and increased to $142.4 \mathrm{MW}$ during the fault period of internal fault then its return to steady state value after fault clearance. On the other hand, it falls to $0 \mathrm{MW}$ during external fault period and returns to steady state value after fault clearance.

\subsection{Impacts of grid voltage sag}

In this subsection, the impacts of different values of grid voltage sags such as 15,30 , and $65 \%$ for a duration of $0.5 \mathrm{~s}$ are studied. The sags of 15,30 , and $65 \%$ mean that the voltage is reduced by 15,30 , and $65 \%$ of the normal value, thus the remaining voltage values are 85,70 , and $35 \%$ respectively. The voltage magnitude variations at group 1 bus and at wind farm PCC bus due to grid voltage sags are shown in Fig. 13a, b. It is noticed that, the measured voltage magnitude at group 1 bus during different grid voltage sags are located above LVRT curve, therefore the proposed protection technique should not isolate the wind turbine generators based on the IEEE Standard 1159-1995. The variations of measured active power at group 1 bus and wind farm PCC bus are shown in Fig. 13c, d respectively. The measured active power at group 1 bus and at wind farm PCC bus is decreased to $38 \mathrm{MW}$ and $179.9 \mathrm{MW}$ in case of voltage sag of $15 \%$ respectively. Also, it decreases to $35.76 \mathrm{MW}$ and $168.7 \mathrm{MW}$ in case of voltage sag of $30 \%$ at group 1 bus and wind farm PCC bus respectively, while it decreases to $16.98 \mathrm{MW}$ and $78.38 \mathrm{MW}$ in case of voltage sag of $65 \%$ for group 1 bus and wind farm PCC bus respectively.

\subsection{Impacts of ground transition resistance}

In this subsection, the impacts of different ground transition resistance $R g$ values on the performance of proposed technique during occurrence of three-phase to ground fault at group 1 for a duration of $150 \mathrm{~ms}$ are investigated. The different studied values of $R g$ are equal to 0,10 and $100 \mathrm{ohms}$, where the variations of measured values of voltage and active power are illustrated in Fig. 14. It is clear that, the performance of proposed protection technique is not affected by the studied different values of $R g$.

\section{Discussion}

In this study, the wind farm is simulated by separated four group generators, where each group has one protection technique based on LVRT requirements. In real wind farm, every wind turbine generator must be equipped with one protection technique according to international standards. The proposed protection technique is based on two approaches, where these approaches are ANFIS fault detector and implementation zones of Egyptian LVRT grid code. During voltage dips, the two approaches of proposed technique discriminate between faulted and un-faulted conditions based on their output control signals. The proposed technique can be applied for the other wind farms based on their LVRT grid code standards. The setting parameters of proposed technique can be modified according to the requirements of other grid codes for different countries. The simulation results indicate that, the validity and robustness of proposed protection technique. Moreover, the proposed protection technique is investigated for different fault conditions to validate their efficiency, effectiveness and accuracy. The proposed technique improves the ability of wind turbine generators to stay connected to electrical grid based on grid code requirements, thus the stability of wind farm is enhanced during different fault conditions. Furthermore, the proposed technique focuses on avoiding trip events of all wind turbine generators during faults and only trip the faulted zone of wind farm for achieving LVRT grid code requirements.

\section{Conclusions}

This paper proposes a design of advanced protection technique for $200 \mathrm{MW}$ Gabal El-Zayt wind farm connected to electrical grid during faults and voltage sag. The studied wind farm generators are divided into four groups, where the capacities of them are $42 \mathrm{MW}, 54 \mathrm{MW}$, $52 \mathrm{MW}$, and $52 \mathrm{MW}$. The proposed protection technique 
Fig. 12 Comparisons of measured values in case of internal and external fault locations a voltage at group 1 bus; b voltage at PCC bus; c active power at group 1 bus; $\mathbf{d}$ active power at PCC bus

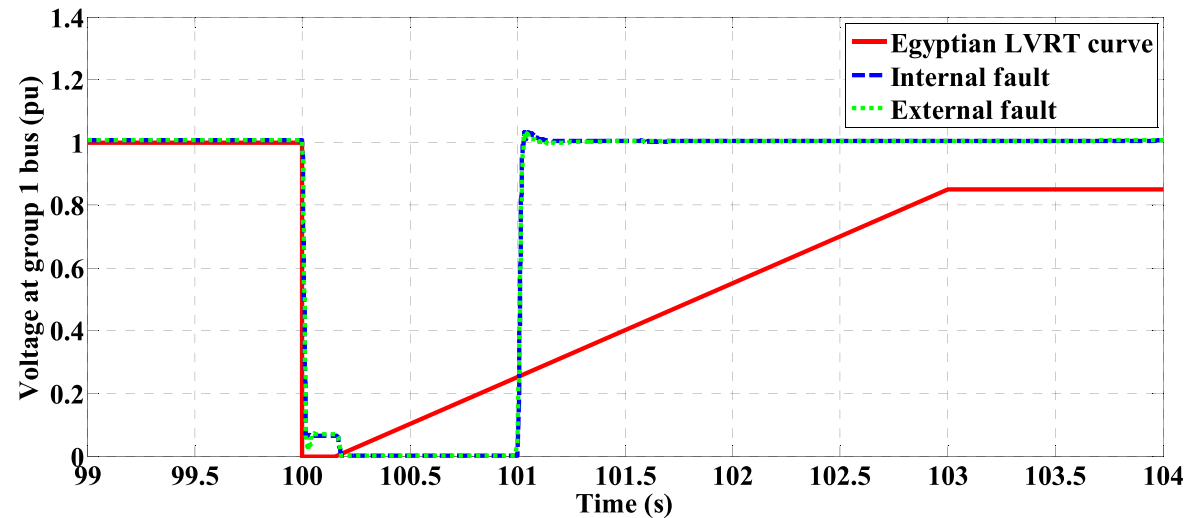

(a)

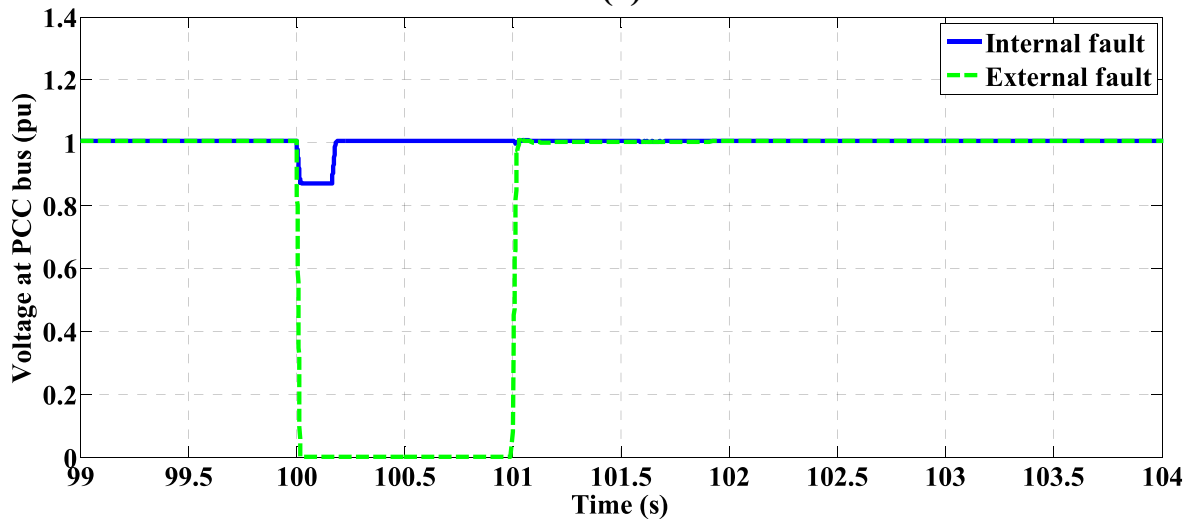

(b)

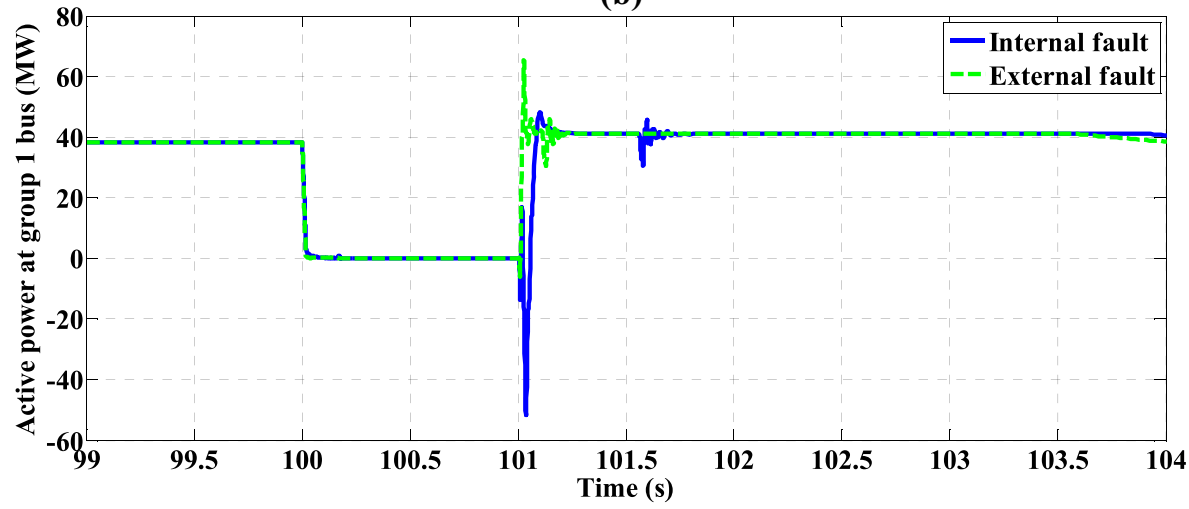

(c)

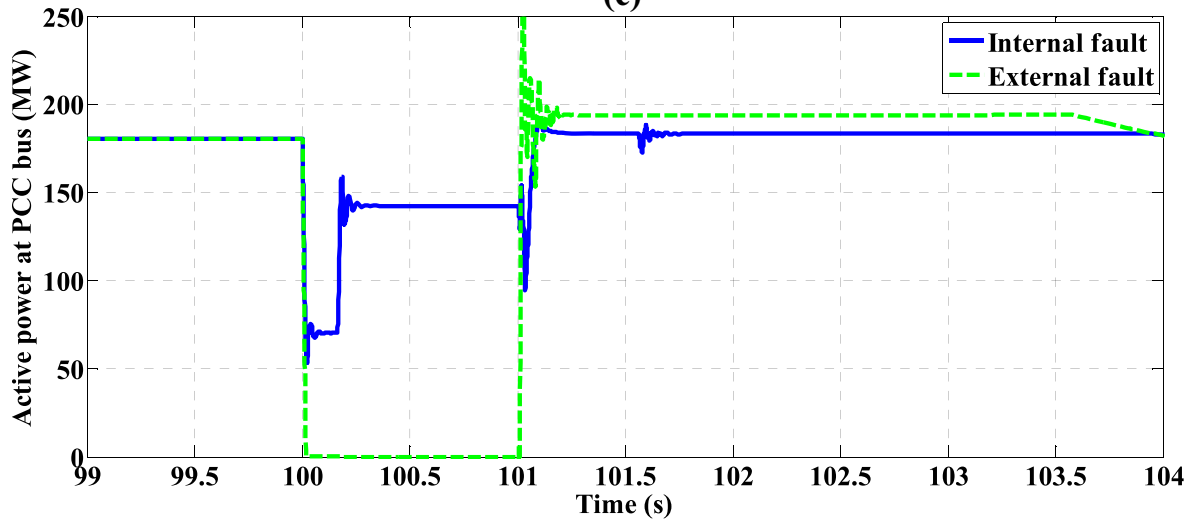

(d) 
Fig. 13 Comparisons of measured values in case of different grid voltage sags a voltage at group 1 bus; $\mathbf{b}$ voltage at PCC bus; $c$ active power at group 1 bus; $\mathbf{d}$ active power at PCC bus

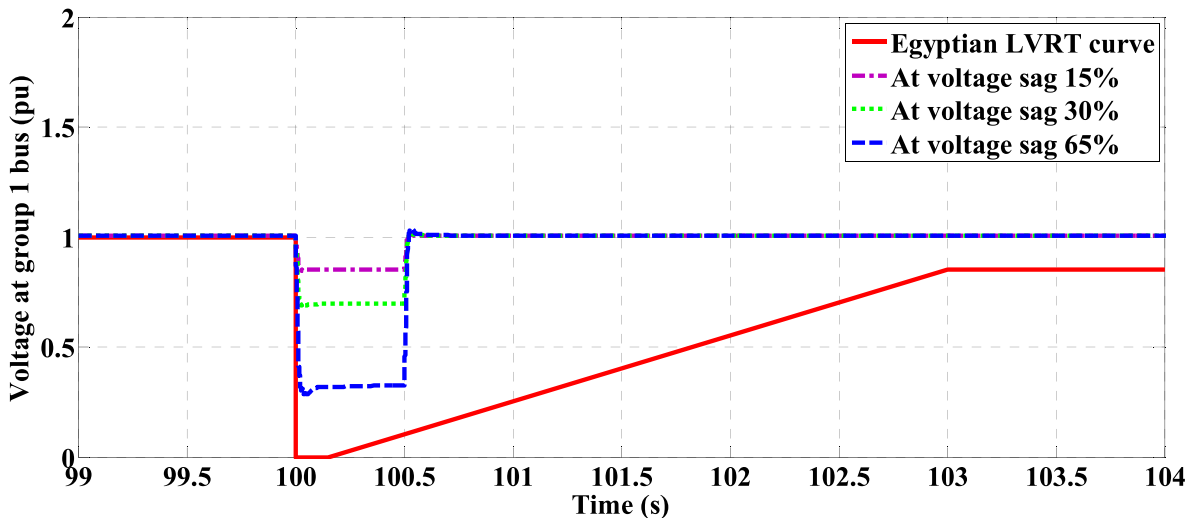

(a)

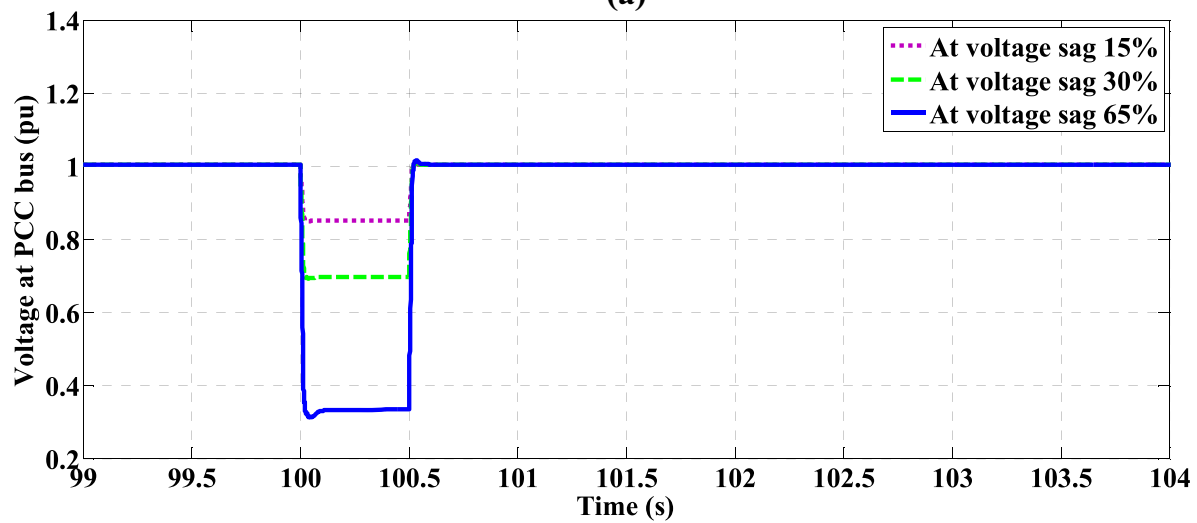

(b)

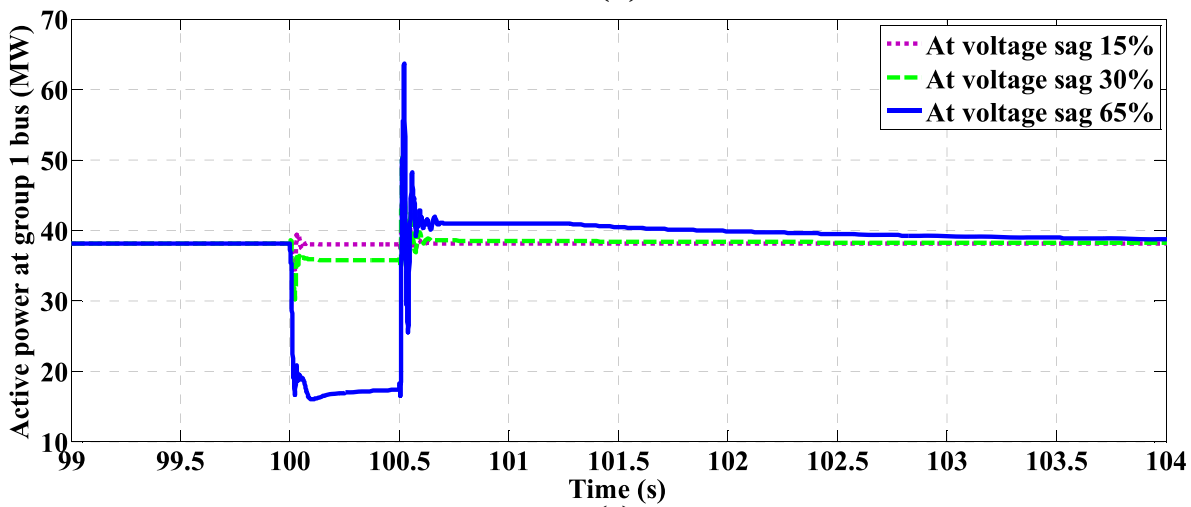

(c)

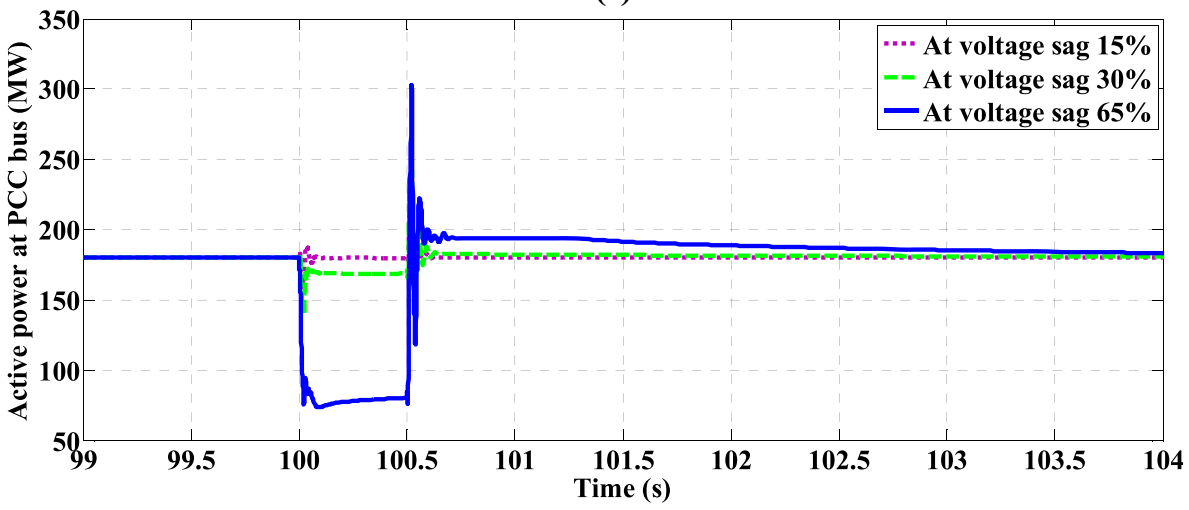

(d) 
Fig. 14 Variations of measured values in case of different ground transition resistances a voltage at group 1 bus; b voltage at PCC bus; c active power at group 1 bus; $\mathbf{d}$ active power at PCC bus

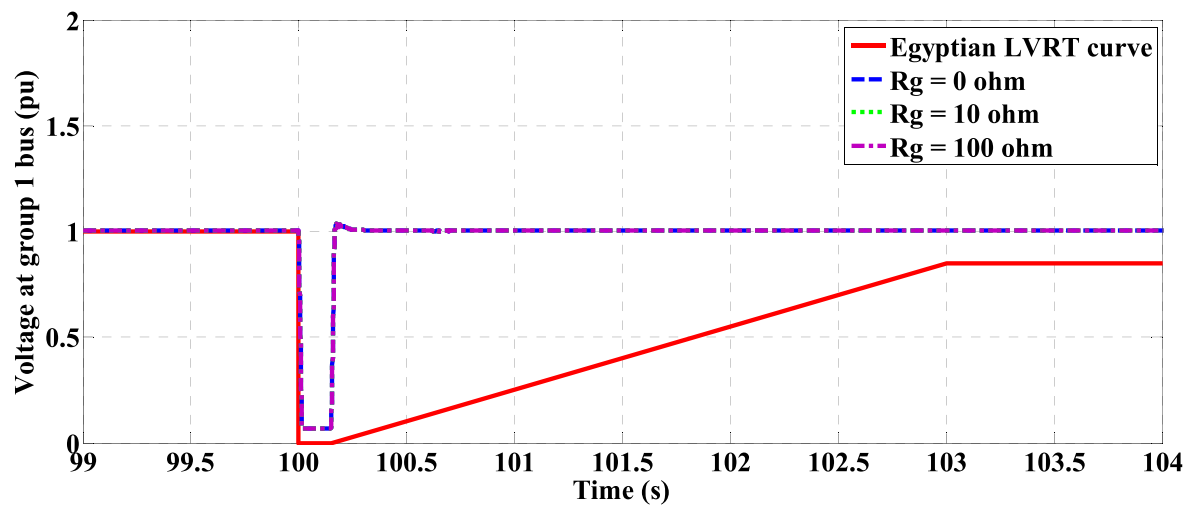

(a)

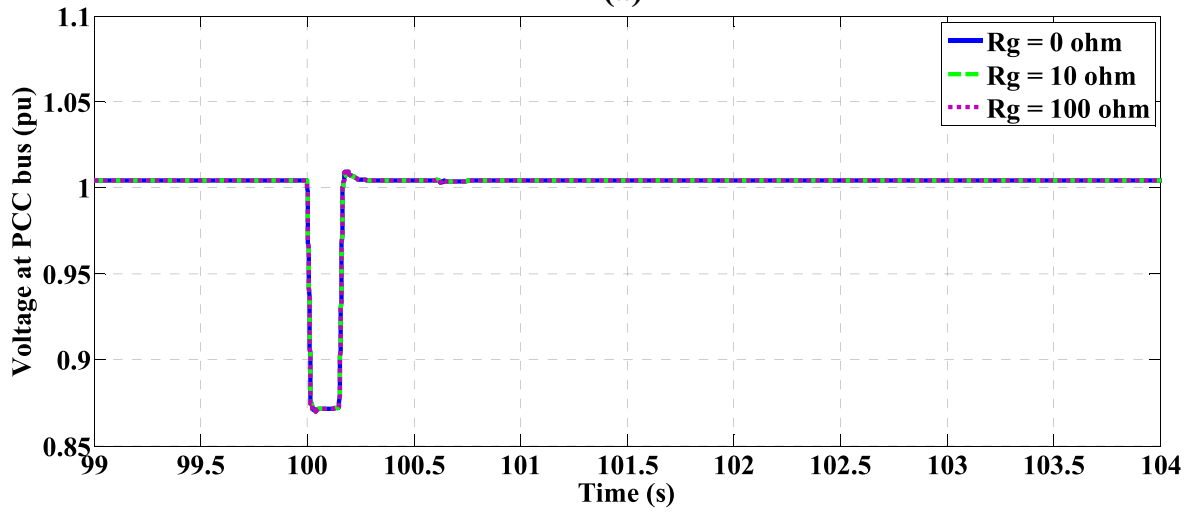

(b)

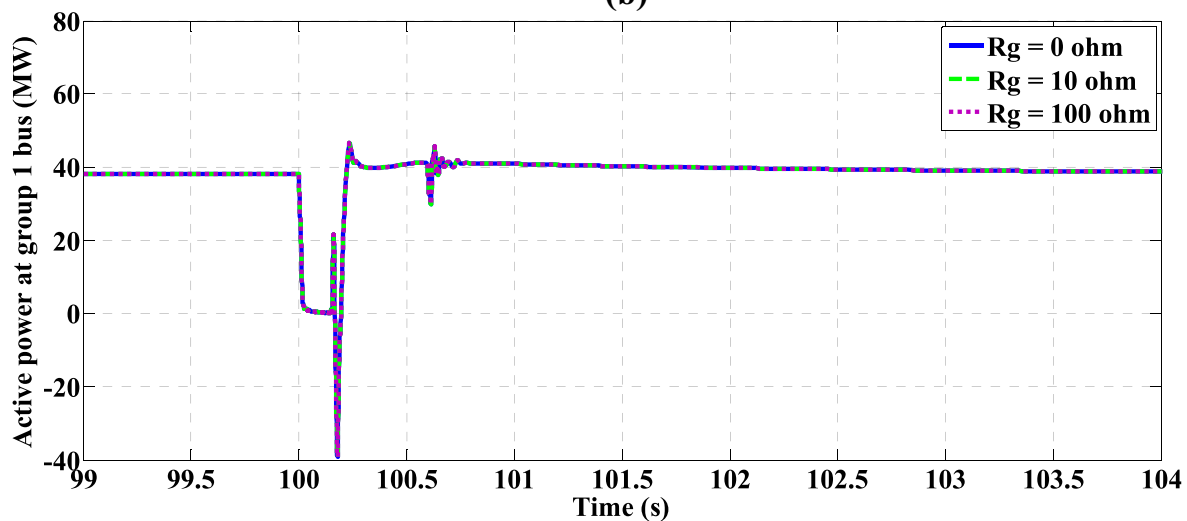

(c)

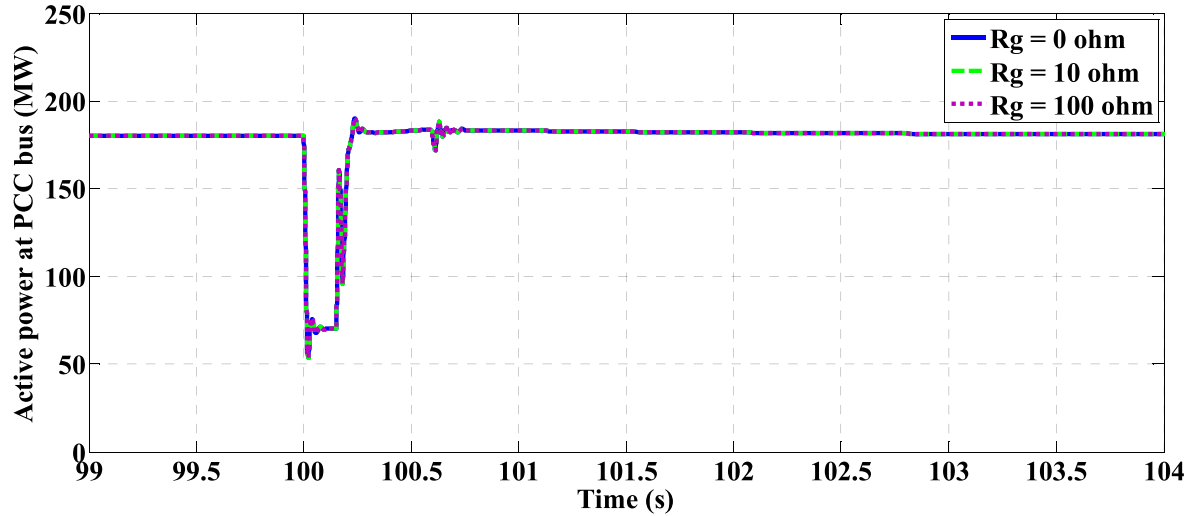

(d) 
consists of two combined approaches which are ANFIS fault detector and implementation of Egyptian LVRT grid code. Firstly, the ANFIS approach is designed to detect the fault occurrence and its location of wind farm. Secondly, the Egyptian LVRT grid code approach is implemented to discriminate between the decision of trip or not trip the faulted wind turbines based on its LVRT grid code requirements. The proposed protection technique is investigated at different fault conditions such as fault duration, fault type, fault location, grid voltage sag, and different ground transition resistances. The fluctuations of voltage level and generated active power are monitored at the buses of wind turbine groups and wind farm PCC for different fault conditions. Different fault durations such as $150 \mathrm{~ms}, 1 \mathrm{~s}$ and $3 \mathrm{~s}$ are studied with different fault types which occurred at the feeder of wind turbine generators group 1. It is obvious that, in case of single-phase to ground fault, the active power at wind farm PCC bus has very little variations which fluctuated between 180.4005 and $180.403 \mathrm{MW}$ for all studied fault durations. On the other hand, in case of double-phase to ground fault, the active power at PCC bus is decreased to 132.6 MW during fault durations of $150 \mathrm{~ms}$ and $1 \mathrm{~s}$, then returns to its normal value after fault clearance, while in case of $3 \mathrm{~s}$ fault duration, it is decreased to $132.6 \mathrm{MW}$ during a certain time and it increases to $142.4 \mathrm{MW}$. Otherwise, in case of three-phase to ground fault, the active power at PCC bus of wind farm is decreased to $70.44 \mathrm{MW}$ for all studied fault periods and it returns to steady state value after fault clearance in case of $150 \mathrm{~ms}$ fault duration, while it returns to $142.4 \mathrm{MW}$ in cases of $1 \mathrm{~s}$ and $3 \mathrm{~s}$ fault durations then returns to steady state value after fault clearance. The simulation results show that, the proposed protection technique can detect the fault locations, hence it isolates the faulted area when the fault duration exceeds a certain time according to the characteristics of Egyptian LVRT grid code during fault occurrence and reconnect it after fault clearance. Finally, the results demonstrate that, the proposed technique enhances the stability of studied wind farm and it can significantly improve the ability of wind turbines to stay connected to the electrical grid during fault occurrence, then consequently fulfilling the Egyptian grid code requirements. Also, the proposed protection technique prevents the cascaded tripping of wind turbine generators during fault occurrence.

\section{Compliance with ethical standards}

Conflict of interest The authors declare that they have no conflict of interest.

\section{References}

1. Abdel Aleem S, Abdelaziz A, Zobaa A (2017) Handbook of distributed generation, Egyptian grid code of wind farms and power quality, vol 7. Springer International Publishing AG, Cham, pp 227-245. https://doi.org/10.1007/978-3-319-51343 $-077$

2. Ministry of Electricity and Renewable Energy (2018) New and renewable energy authority (NREA) annual report for the Egypt. http://www.nrea.gov.eg/Content/reports/Englishv2A nnualReport.pdf

3. Noureldeen O, Rashad A (2014) Modeling and investigation of Gulf El-Zayt wind farm for stability studying during extreme gust wind occurrence. Ain Shams Eng J 5:137-148

4. Hassan M, Helmi D, Elshahed M, Abd-Elkhalek H (2017) Improving the capability curves of a grid-connected wind farm: Gabel El-Zeit, Egypt. In: Proceedings of IEEE, nineteenth international middle east power systems conference (MEPCON). Cairo, 19-21 Dec 2017, pp 300-307

5. Uddin W, Zeb K, Tanoli A, Haider A (2018) Hardware-based hybrid scheme to improve the fault ride through capability of doubly fed induction generator under symmetrical and asymmetrical fault. IET Gener Transm Distrib 12(1):200-206

6. Noureldeen O, Hamdan I (2018) A novel controllable crowbar based on fault type protection technique for DFIG wind energy conversion system using adaptive neuro-fuzzy inference system. Prot Control Modern Power Syst 3(35):1-12

7. Noureldeen O, Hamdan I (2017) An efficient ANFIS crowbar protection for DFIG wind turbines during faults. In: Proceedings of IEEE, nineteenth international middle east power systems conference (MEPCON). Cairo, 19-21 Dec 2017, pp 263-269

8. Guo W, Xiao L, Dai S, Li Y, Xu X, Zhou W, Li L (2015) LVRT Capability enhancement of DFIG with switch-type fault current limiter. IEEE Trans Ind Electron 62(1):332-342

9. Cárdenas R, Peña R, Alepuz S, Asher G (2013) Overview of control systems for the operation of DFIGs in wind energy applications. IEEE Trans Ind Electron 60(7):2776-2798

10. Hossain M, Saha T, Mithulananthan N, Pota H (2013) Control strategies for augmenting LVRT capability of DFIGs in interconnected power systems. IEEE Trans Ind Electron 60(6):2510-2522

11. Ravichandran S, Kumudinidevi R, Bharathidasan S, Jeba V (2014) Coordinated controller design of grid connected DFIG based wind turbine using response surface methodology and NSGA II. Sustain Energy Technol Assess 8:120-130

12. Hu Y-L, Wua Y-K, Chen C-K, Wang C-H, Chen W-T, Cho L-I (2017) A review of the low-voltage ride-through capability of wind power generators. Energy Procedia 141:378-382

13. Noureldeen $\mathrm{O}$ (2011) Low voltage ride through strategies for SCIG wind turbines interconnected grid. Int J Electr Comput SCi IJECS-IJENS 11(2):59-64

14. Noureldeen O, Hamdan I (2018) Design of robust intelligent protection technique for large-scale grid-connected wind farm. Prot Control Modern Power Syst 3(17):1-13

15. Moussavi SZ, Kashkooli FR (2013) Small signal stability assessment of power systems with large-scale wind farms. Arab J Sci Eng 38:2493-2502

16. Yang S, Zhou T, Sun D, Xie Z, Zhang X (2016) A SCR crowbar commutated with power converter for DFIG-based wind turbines. Int J Electr Power Energy Syst 81:87-103

17. Guo W, Xiao L, Dai S (2016) Fault current limiter-battery energy storage system for the doubly-fed induction generator: analysis and experimental verification. IET Gener Transm Distrib 10(3):653-660 
18. Swain S, Ray P (2017) Short circuit fault analysis in a grid connected DFIG based wind energy system with active crowbar protection circuit for ridethrough capability and power quality improvement. Int J Electr Power Energy Syst 84:64-75

19. Jerin R, Kaliannan P, Subramaniam U (2017) Testing of low voltage ride through capability compliance of wind turbines-a review. Int J Ambient Energy 39(8):891-897

20. Sitharthan R, Geethanjali M (2015) Application of the superconducting fault current limiter strategy to improve the fault ridethrough capability of a doubly-fed induction generator-based wind energy conversion system. Simul Trans Soc Model Simul Int 91(12):1081-1087

21. Rahmann C, Haubrich H-J, Moser A, Palma-Behnke R, Vargas $L$, Salles MBC (2011) Justified fault-ride-through requirements for wind turbines in power systems. IEEE Trans Power Syst 26(3):1555-1563

22. Ling $Y$ (2016) The fault ride through technologies for doubly fed induction generator wind turbines. Wind Eng 40(1):31-49

23. Leão RPS, Almada JB, Souza PA, Cardoso RJ, Sampaio RF, Lima FKA, Silveira JG, Formiga LEP (2010) The implementation of the low voltage ride-through curve on the protection system of a wind power plant. In: International conference on renewable energies and power quality. Las Palmas de Gran Canaria, 13-15 April 2010, pp 1312-1317

24. Muyeen SM, Takahashi R, Murata T, Tamura J, Ali MH, Matsumura Y, Kuwayama A, Matsumoto T (2009) Low voltage ride through capability enhancement of wind turbine generator system during network disturbance. IET Renew Power Gener 3(1):65-74

25. Liang J, Qiao W, Harley RG (2010) Feed-forward transient current control for low-voltage ride-through enhancement of DFIG wind turbines. IEEE Trans Energy Convers 25(3):836-843

26. Chowdhury M, Sayem A, Shen W, Islam K (2015) Robust active disturbance rejection controller design to improve low-voltage ride-through capability of doubly fed induction generator wind farms. IET Renew Power Gener 9(8):961-969

27. Mohammadi J, Afsharnia S, Ebrahimzadeh E, Blaabjerg F (2017) An enhanced LVRT scheme for DFIG-based WECSs under both balanced and unbalanced grid voltage sags. Electr Power Compon Syst 45(11):1242-1252

28. Xie Z, Zhang X, Zhang X, Yang S, Wang L (2015) Improved ridethrough control of DFIG during grid voltage swell. IEEE Trans Ind Electron 62(6):3584-3594

29. Chen L, Zheng F, Deng C, Li Z, Guo F (2015) Fault ride-through capability improvement of DFIG-based wind turbine by employing a voltage-compensation-type active SFCL. Can J Electr Comput Eng 38(2):132-142

30. Liu S, Bi T, Jia K, Yang Q (2016) Coordinated fault-ride-through strategy for doubly-fed induction generators with enhanced reactive and active power support. IET Renew Power Gener 10(2):203-211

31. Justo J, Mwasilu F, Jung J (2015) Doubly-fed induction generator based wind turbines: a comprehensive review of fault ridethrough strategies. Renew Sustain Energy Rev 45:447-467

32. Mendes V, de Sousa C, Hofmann W, Silva S (2015) Doubly-fed induction generator ride-through fault capability using resonant controllers for asymmetrical voltage sags. IET Renew Power Gener 9(7):783-791

33. Mohammadi J, Afsharnia S, Vaez-Zadeh S (2014) Efficient faultride-through control strategy of DFIG-based wind turbines during the grid faults. Energy Convers Manag 78:88-95
34. Wang S, Chen N, Yu D, Foley A, Zhu L, Li K, Yu J (2015) Flexible fault ride through strategy for wind farm clusters in power systems with high wind power penetration. Energy Convers Manag 93:239-248

35. Noureldeen O, Youssef MMM, Hassanin B (2019) Stability improvement of $200 \mathrm{MW}$ Gabal El-Zayt wind farm connected to electrical grid using supercapacitor and static synchronous compensator during extreme gust. SN Appl Sci. https://doi. org/10.1007/s42452-019-0351-5

36. Ghosh S, Kamalasadan S (2017) An energy function-based optimal control strategy for output stabilization of integrated DFIG-flywheel energy storage system. IEEE Trans Smart Grid 8(4):1922-1931

37. Kenan DM (2017) Enhancement of SDRU and RCC for low voltage ride through capability in DFIG based wind farm. Electr Eng 99(2):673-683

38. Li W, Joos G, Belanger J (2010) Real-time simulation of a wind turbine generator coupled with a battery supercapacitor energy storage system. IEEE Trans Ind Electron 57(4):1137-1145

39. Kenan DM (2016) A new approach for low voltage ride through capability in DFIG based wind farm. Int J Electr Power Energy Syst 83:251-258

40. Kalantar M, Mousavi GMS (2010) Dynamic behavior of a stand-alone hybrid power generation system of wind turbine, microturbine, solar array and battery storage. Appl Energy 87(10):3051-3064

41. Kenan DM (2017) Nonlinear dynamic modeling for fault ridethrough capability of DFIG-based wind farm. Nonlinear Dyn 89(4):2683-2694

42. Rahimi M, Parniani M (2010) Coordinated control approaches for low-voltage ride-through enhancement in wind turbines with doubly fed induction generators. IEEE Trans Energy Convers 25(3):873-883

43. Kenan DM (2016) Hybrid low voltage ride through enhancement for transient stability capability in wind farms. Int J Electr Power Energy Syst 78:655-662

44. Rahimi M, Parniani M (2014) Low voltage ride-through capability improvement of DFIG-based wind turbines under unbalanced voltage dips. Int J Electr Power Energy Syst 60:82-95

45. Noureldeen O, Hamdan I (2018) Design and analysis of combined chopper-crowbar protection scheme for wind power system based on artificial intelligence. In: Proceedings of IEEE, twentieth international middle east power systems conference (MEPCON). Cairo, 18-20 Dec 2018, pp 809-814

46. Suganthi L, Iniyan S, Samuel AA (2015) Applications of fuzzy logic in renewable energy systems-a review. Renew Sustain Energy Rev 48:585-607

47. Shihabudheen KV, Raju SK, Pillai GN (2018) Control for gridconnected DFIG-based wind energy system using adaptive neuro-fuzzy technique. Int Trans Electr Energy Syst 28(5):1-18

48. (1995) IEEE Recommended Practice for Monitoring Electric Power Quality. IEEE, IEEE Std: 1159-1995. https://doi. org/10.1109/IEEESTD.1995.79050

Publisher's Note Springer Nature remains neutral with regard to jurisdictional claims in published maps and institutional affiliations. 